NATIONAL LABORATORY

MANAGED BY UT-BATTELLE

FOR THE DEPARTMENT OF ENERGY

\title{
Analysis of DOE's Roof Savings Calculator with Comparison to other Simulation Engines
}

January 2014

Prepared by

Joshua New

Contributing Authors

Joshua New

William A. Miller

Yu (Joe) Huang

Ronnen Levinson

Jibonananda Sanyal

Kenneth Childs

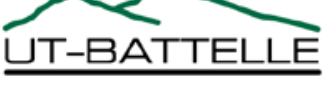




\section{DOCUMENT AVAILABILITY}

Reports produced after January 1, 1996, are generally available free via the U.S. Department of Energy (DOE) Information Bridge.

Web site http://www.osti.gov/bridge

Reports produced before January 1, 1996, may be purchased by members of the public from the following source.

National Technical Information Service

5285 Port Royal Road

Springfield, VA 22161

Telephone 703-605-6000 (1-800-553-6847)

TDD 703-487-4639

Fax 703-605-6900

E-mail info@ntis.gov

Web site http://www.ntis.gov/support/ordernowabout.htm

Reports are available to DOE employees, DOE contractors, Energy Technology Data Exchange (ETDE) representatives, and International Nuclear Information System (INIS) representatives from the following source.

Office of Scientific and Technical Information

P.O. Box 62

Oak Ridge, TN 37831

Telephone 865-576-8401

Fax 865-576-5728

E-mail reports@osti.gov

Web site http://www.osti.gov/contact.html

This report was prepared as an account of work sponsored by an agency of the United States Government. Neither the United States Government nor any agency thereof, nor any of their employees, makes any warranty, express or implied, or assumes any legal liability or responsibility for the accuracy, completeness, or usefulness of any information, apparatus, product, or process disclosed, or represents that its use would not infringe privately owned rights. Reference herein to any specific commercial product, process, or service by trade name, trademark, manufacturer, or otherwise, does not necessarily constitute or imply its endorsement, recommendation, or favoring by the United States Government or any agency thereof. The views and opinions of authors expressed herein do not necessarily state or reflect those of the United States Government or any agency thereof. 


\title{
Analysis of DOE's Roof Savings Calculator with Comparison to other Simulation Engines
}

\author{
Joshua New \\ William A. Miller \\ Yu (Joe) Huang \\ Ronnen Levinson \\ Jibonananda Sanyal \\ Kenneth Childs
}

October 2013

\author{
Prepared by \\ OAK RIDGE NATIONAL LABORATORY \\ Oak Ridge, Tennessee 37831-6283 \\ managed by \\ UT-BATTELLE, LLC \\ for the \\ U.S. DEPARTMENT OF ENERGY \\ under contract DE-AC05-00OR22725
}





\section{Contents}

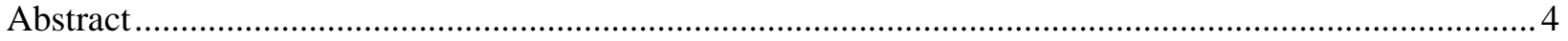

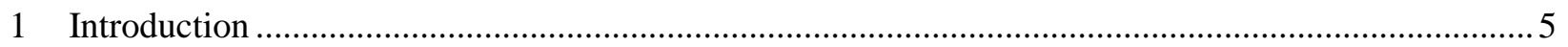

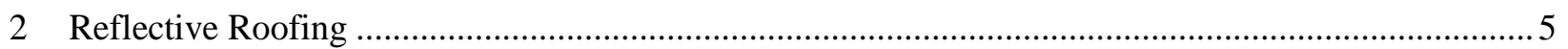

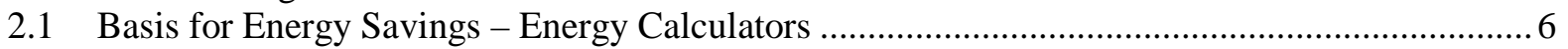

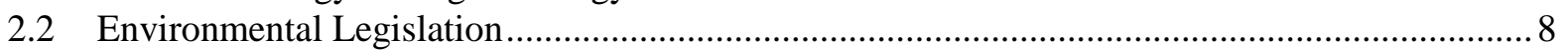

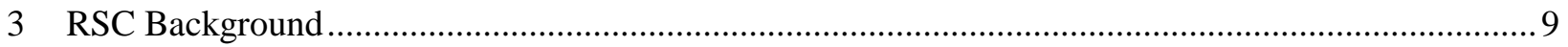

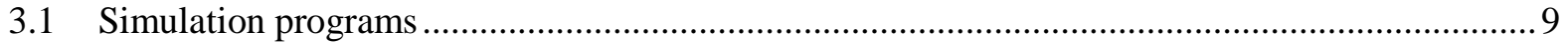

3.1.1 DOE-2.1E

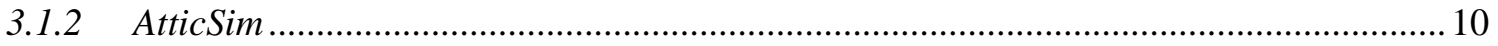

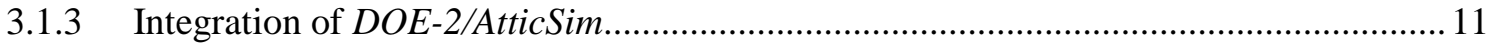

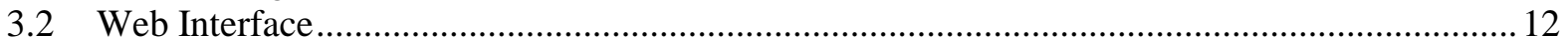

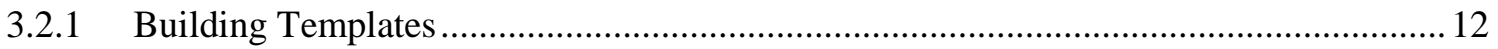

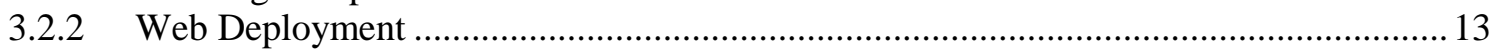

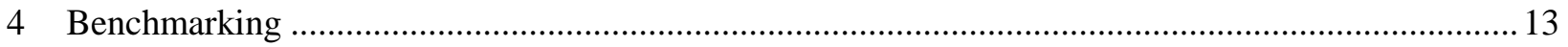

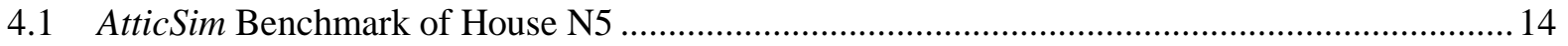

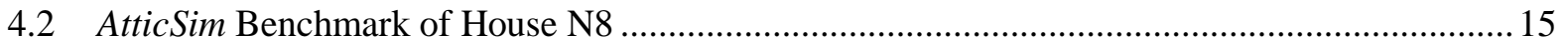

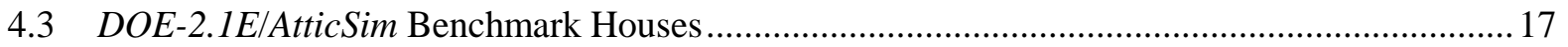

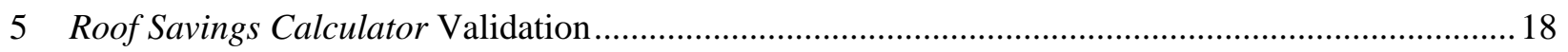

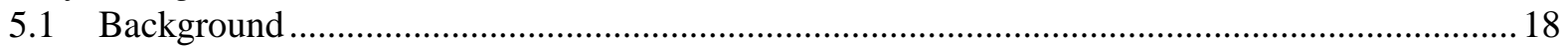

5.2 Comparison of RSC to previous LBNL studies .................................................................. 19

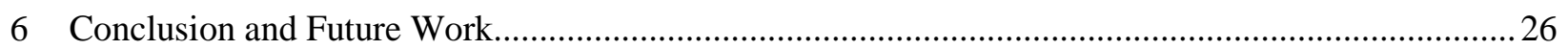

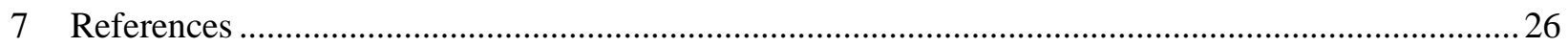

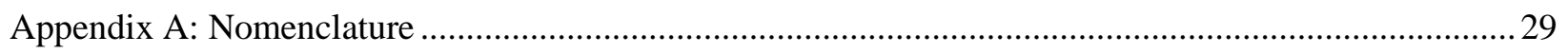

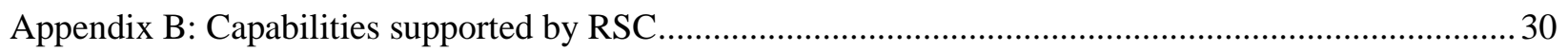

Appendix C: Cooling site energy savings and heating site energy penalty comparison............................31

Appendix D: Base case electricity and gas use comparison ................................................................ 33

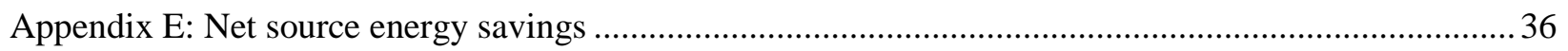

Appendix F: Details of old office and new home simulations............................................................... 37

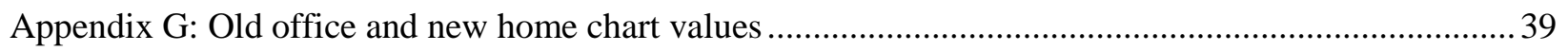

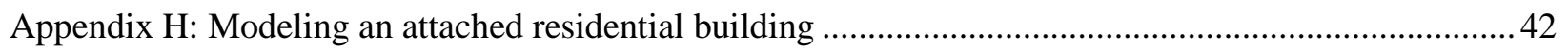

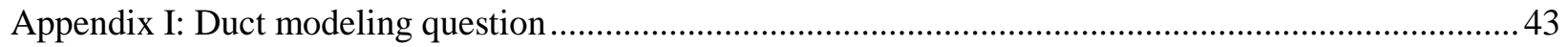

Appendix J: Preliminary analysis on the force multiplier of rsc heating penalties and the role of radiative

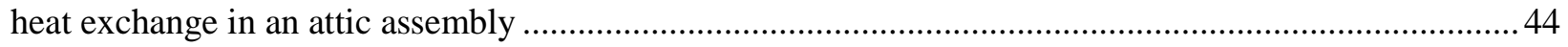

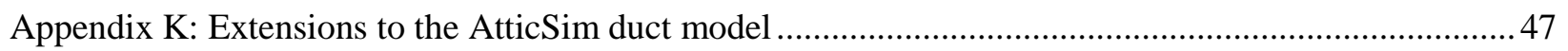

Appendix L: Lessons learned in ensemble comparison of RSC simulations............................................. 53 


\begin{abstract}
A web-based Roof Savings Calculator (RSC) has been deployed for the Department of Energy as an industry-consensus tool to help building owners, manufacturers, distributors, contractors and researchers easily run complex roof and attic simulations. This tool employs the latest web technologies and usability design to provide an easy input interface to an annual simulation of hour-by-hour, whole-building performance using the world-class simulation tools DOE-2.1E and AtticSim. Building defaults were assigned based on national averages and can provide estimated annual energy and cost savings after the user selects nothing more than building location.

In addition to cool reflective roofs, the RSC tool can simulate multiple roof and attic configurations including different roof slopes, above sheathing ventilation, radiant barriers, low-emittance surfaces, HVAC duct location, duct leakage rates, multiple layers of building materials, and ceiling and deck insulation levels. A base case and energy-efficient alternative can be compared side-by-side to generate an energy/cost savings estimate between two buildings. The RSC tool was benchmarked against field data for demonstration homes in Ft. Irwin, CA. However, RSC gives different energy savings estimates than previous cool roof simulation tools so more thorough software and empirical validation proved necessary. This report consolidates much of the preliminary analysis for comparison of $R S C$ 's projected energy savings to that from other simulation engines.
\end{abstract}




\section{INTRODUCTION}

The Roof Savings Calculator (RSC) was developed through collaborations among Oak Ridge National Laboratory (ORNL), White Box Technologies (WBT), Lawrence Berkeley National Laboratory (LBNL), and the Environmental Protection Agency (EPA) in the context of a California Energy Commission (CEC) Public Interest Energy Research (PIER) project to make cool colored roofing materials a market reality. The $R S C$ website [1] and a simulation engine validated against demonstration homes was developed to replace the liberal DOE Roofing Calculator [2] and the conservative EPA Energy Star Roofing Calculator [3], which reported different roof savings estimates.

The primary objective with this calculator was to develop a web-based tool with which users can easily estimate realistic cooling energy savings achieved by installing cool roofing products on the most common residential and commercial building types in the US stock. Goals included development of a fast simulation engine benchmarked against cool-colored roofing materials, educating the public with regard to cool roofing options and savings, helping manufacturers of cool-colored materials deploy their products, and assisting utilities and public interest organizations to refine incentive programs for cool roofs. Recent emphasis on domestic building energy use, market penetration for cool roofing products, and job creation has made the work a top priority of the Department of Energy's (DOE) Building Technologies Office (BTO).

\section{REFLECTIVE ROOFING}

For more than 30 years, roof coating products have been available to the roofing market in the form of asphaltic-based mastics and coatings, emulsion coatings, fibered and non-fibered aluminum, acrylic coatings, polyurethanes, polyureas, epoxies, methyl methacrylates, etc. Polyvinylidene difluorides are often available as a factory-applied coating for metal roofs. For just as many years, modified bitumen membranes have existed in the form of mineral, smooth, foil-faced, and film-surfaced with base chemistries of styrene butadiene styrene (SBS), attactic polypropylene (APP), and a variety of other chemistries. There are single ply options (such as EPDM, TPO, KEE, and PVC) and metal options, most notably, standing seam solutions in a myriad of colors. Built up roofing systems with asphalt or tar, cold or hot applied, with aggregate or mineral surfaces are also prevalent. Similar reflective roofing technologies are applied to common roofing types including clay tile, concrete pavers, and asphalt shingles. Each product has its specific advantages, performance attributes, economic impact, life-cycle expectations, and limitations.

Given these facts, product selection and design decisions can be highly complex and, in some cases, risky. It is therefore critical to work with industry experts, roofing professionals, and reputable companies when selecting a roofing solution. Furthermore, using independent agencies such as American Society of Testing and Materials (ASTM), Underwriters Laboratories (UL), Factory Mutual (FM), the Cool Roof Rating Council (CRRC), the Canadian Construction Materials Centre (CCMC), Deutsches Institut fur Normung e.V. (DIE), or independent test laboratories to assist in verifying quality and behavior helps to validate product claims and performance. New and existing qualifying agencies such as the International Building Code (IBC), the U.S. Green Building Council's Leadership in Energy and Environmental Design (USGBC-LEED), the International Green Building Council (IGBC), the California Energy Commission (CEC), the American Society of Heating, Refrigerating, and Air Conditioning Engineers (ASHRAE) can help building owners and facility managers make appropriate decisions by offering design requirements and establishing building codes. Over the last decade, much of the development, 
design, and code alterations have focused on enhancing overall construction sustainability, the use of green product solutions, and an emphasis on cool roofing solutions.

The cool roofing initiative was the result of studies performed in the 1980s establishing a phenomenon known as the urban heat island effect which is the thermal property of metropolitan areas to remain hotter longer than areas of less building density as shown in Figure 1.

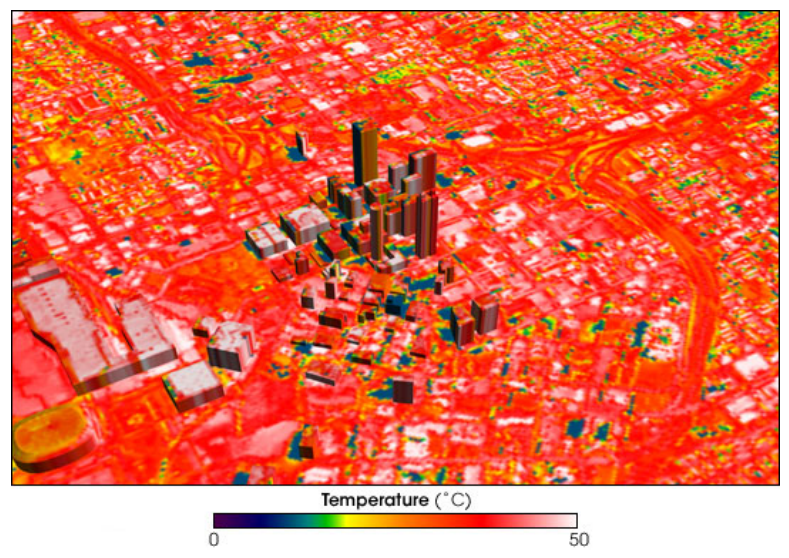

Figure 1. Thermal, infrared image of downtown Atlanta, GA

The infrared photo shows that the occupied areas in and around downtown Atlanta stay hotter longer, not only affecting the nearby environment, but also driving up energy costs to cool the interiors of the building. Academic studies and discussions regarding how to solve these issues include creating more green space, replacing parking lots with grass surfacing, utilizing the roof top as a passive solar heater, additional shading for window designs, and the reduction in black surfaces by replacing dark surfaced roofs, roads, and parking facilities with more reflective surfaces.

\subsection{BASIS FOR ENERGY SAVINGS - ENERGY CALCULATORS}

There are a variety of calculators available for public use. In most cases, users have the ability to input data for a broad group of variables including but not limited to location, building type, HVAC efficiencies and type, roof type, solar reflectance, thermal emittance, and level of insulation. Based upon the information provided, the calculator uses mathematical models that return energy usage based on local climatic conditions.

The most common environmental conditions used in a typical analysis are solar irradiance, cooling degree days, and heating degree days. "Cooling degree days", or "CDD", are a measure of how much (in degrees), and for how long (in days), outside air temperature was higher than a specific base temperature. They are used for calculations relating to the energy consumption required to cool buildings. "Heating degree days", or "HDD", are a measure of how much (in degrees), and for how long (in days), outside air temperature was lower than a specific "base temperature" (or "balance point"). They are used for calculations relating to the energy consumption required to heat buildings. Maps shown in Figure 2 outline the cooling degree days and heating degree days for locations throughout the United States. 

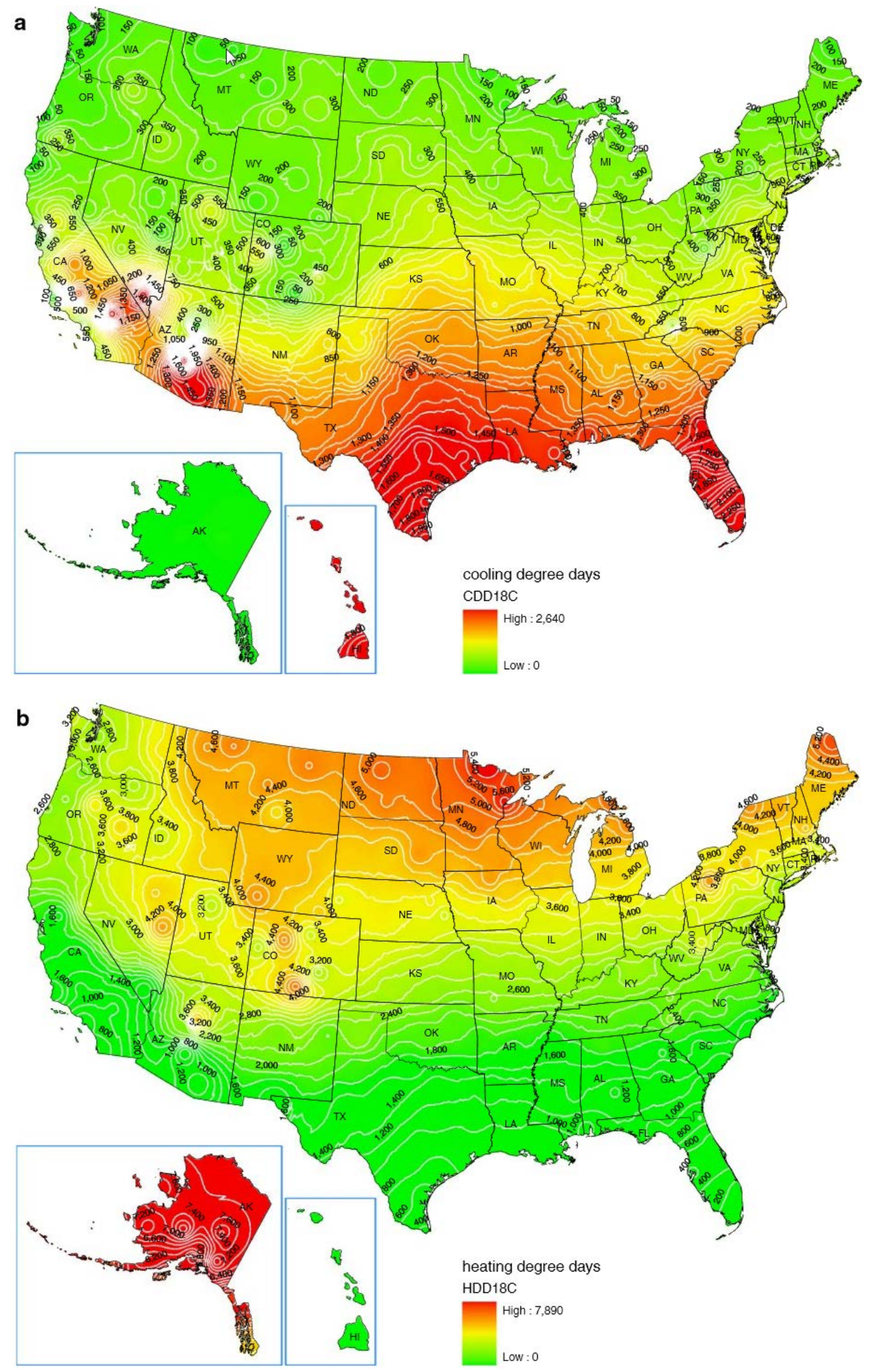

Figure 2. Maps of (a) annual cooling degree days (CDD18C), and (b) annual heating degree days (HDD18C) computed from TMY2 typical meteorological year data [36] 
Intuitively, Houston (HDD=1500, CDD=3000) would typically spend more days cooling their buildings versus heating their buildings; conversely, in Minneapolis (HDD=8000, $C D D=500)$, more days require heating versus cooling.

Solar irradiance is a measure of the rate at which solar radiation that is received at a specific location. In general, hotter climates like Phoenix have higher solar irradiance than a more temperate climate like Chicago.

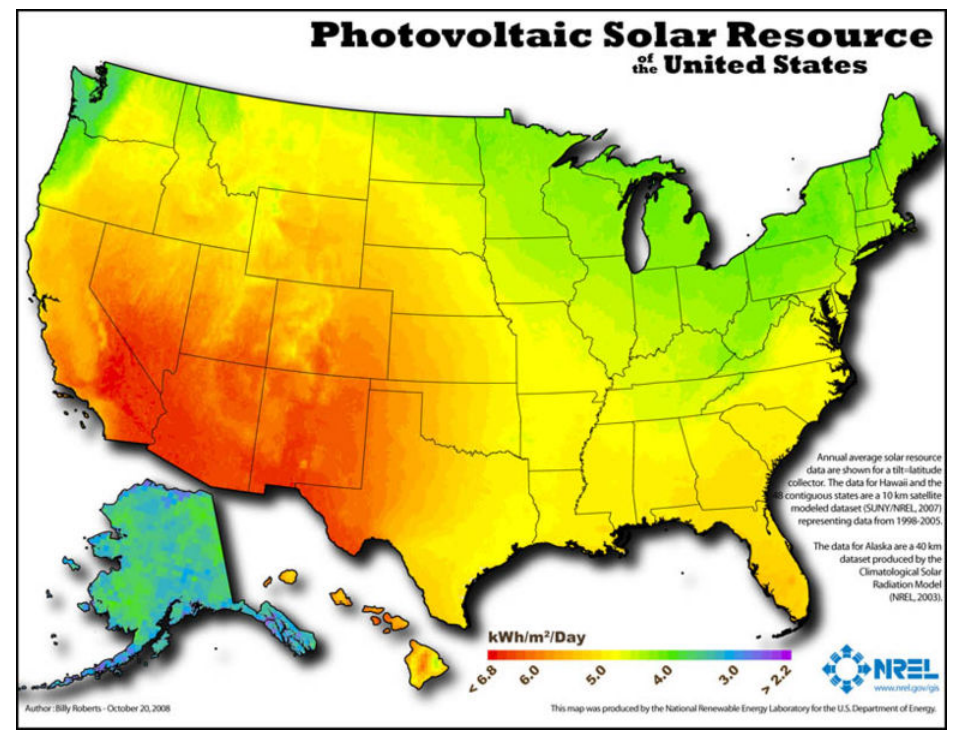

Figure 3. U.S. Direct Normal Solar Radiation (NREL 2005 [30])

By combining such environmental factors with building-specific inputs (such as solar reflectance, level of insulation, etc.), one can use the algorithmic simulation engines of these calculators to generate energy consumption figures. By systematically comparing different simulation conditions, one can calculate the potential savings created by making specific construction changes to the roofing system. For this report, the Roof Savings Calculator hosted at the Oak Ridge National Laboratory was used for all reported data.

\subsection{ENVIRONMENTAL LEGISLATION}

Much of the country has adopted cool roofing practices by increasing insulation or increasing the use of reflective surfacing. For example, ASHRAE Standard 90.1-2007 allowed reduced insulation if cool roofing is used in Zones 1, 2, and 3. However, higher solar reflectance and increased roof insulation levels without tradeoffs are required by section 5.5.3.1.1 of ASHRAE 90.1-2010 [31]. Cool roofing is usually defined in terms of solar reflectance, where solar spectrum is defined as $0.3-2.5 \mu \mathrm{m}$, and thermal emittance, 4-80 $\mu \mathrm{m}$, or in terms of the solar reflectance index which combines the two as defined by ASTM E1980-11 and can be calculated with online tools [32]. Cool roofing is defined by a surface solar reflectance of 70\% and a thermal emittance of 0.75 (SRI 83). ASHRAE 90.2, Energy Efficient Design of Low-Rise Residential Buildings, allows for reduced insulation for a solar reflectance level of 0.65 (SRI 75). LEED provides credit for the use of reflective coatings (higher than 78 SRI) in all areas.

Many states, locations and power authorities provide credits, rebates, and incentives to utilize reflective systems. A lengthy list of these opportunities can be found on the CRRC (Cool Roof Rating Council) website [33]. A number of temperate or cool climates provide incentives (or requirements) for cool roofing such as Idaho, Ohio, Colorado, Illinois and Minnesota. It is important to note that consumers who 
choose a reflective roofing solution in such climatic regions may not receive the same financial benefit from energy savings as they might in warmer climates.

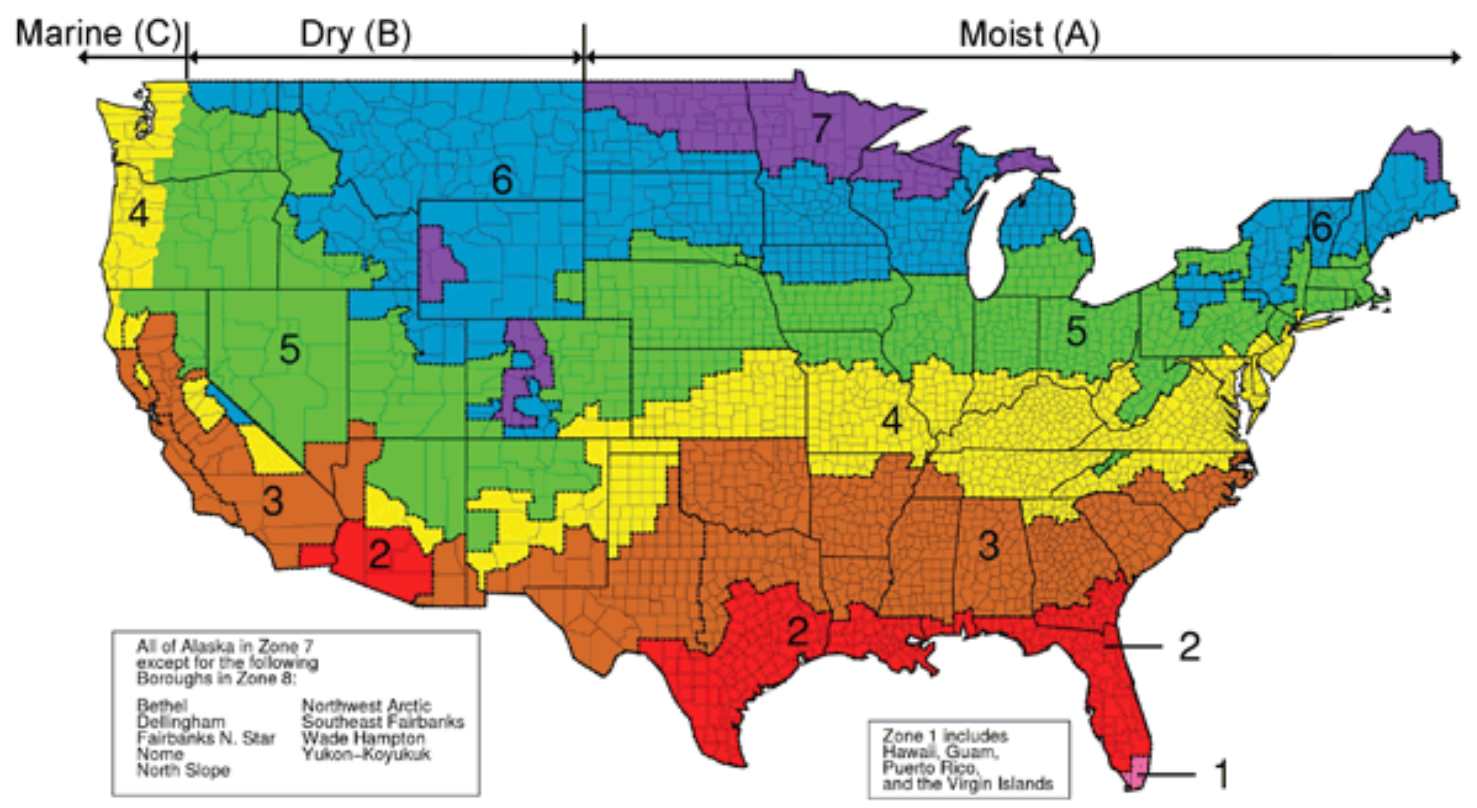

Figure 4. U.S. map of ASHRAE climate zones.

\section{RSC BACKGROUND}

The Roof Savings Calculator (RSC) is a web-accessible tool that leverages AtticSim for advanced modeling of modern attic and cool roofing technologies in combination with hour-by-hour building energy performance provided by $D O E-2.1 E$ to provide simulations that quantify annual energy and cost savings between a customizable baseline building and a cool-roof building. We discuss some history and the motivation to use each of these software codes, discuss the web-interface briefly, and discuss a validation experiment that was conducted initially which led to a more comprehensive validation of the DOE Roof Savings Calculator.

\subsection{SIMULATION PROGRAMS}

\subsubsection{DOE-2.1E}

$D O E-2.1 E$ [4] is a whole-building energy simulation program that was originally developed by Lawrence Berkeley National Laboratory in the early 1980s (Version 2.1A) [5] , with continued development through 1993 (Versions 2.1B through 2.1E) [6]. DOE-2.1E is the most current version of DOE-2 that is in the public domain, although there are later efforts and user-interfaces developed by private companies. Counting its many versions and user interfaces, DOE-2 is the most widely used building energy simulation program in the world today. It has been the basis of most performance-based building energy standards in the United States and at least ten other countries, as well as being used for voluntary "Green Building” rating systems such as the US Green Building Council’s Leadership in Energy and Environmental Design (LEED). 
DOE-2 itself is an engineering program, with a text-based input and output procedure. The program takes as input a description of the physical building and its space conditioning system, its internal conditions (schedules for occupancy and lighting), operations (thermostat schedules), and the hourly weather conditions (air temperature, humidity, wind speed, and solar radiation), and produces as output the energy consumption, as well as the indoor conditions, of the building. Using the program is difficult because it requires in-depth knowledge of both how $D O E$-2 works and how buildings are constructed and operated. Although there are numerous papers attesting to the fundamental soundness of the $D O E-2$ program, the fact remains that a computer model is only as good as the inputs. The multiplicity of inputs can cause confounding results.

DOE-2 operates on an hourly time-step, and uses response factors to model the dynamic heat flows through the building envelope. At the zone level, DOE-2 uses weighting factors (also called zone response factors) to model the dynamic response of the space, taking into account its thermal mass (capacitance) and heat transfer through radiation and/or convection. DOE-2 is made up of two programs, an input processing program called doebdl and a simulation program called doesim, which is composed of four separate modules called sequentially by DOE-2.1E. The LOADS module simulates the heat flows in and out of the building and calculates the net balance at a fixed reference temperature, negative being interpreted as a heating load and positive as a cooling load. The SYSTEMS module takes the results from LOADS, simulates the operation of the HVAC system, and derives the actual zone temperatures, amount of heating and cooling provided by the system, and the energy consumed. If the building has a central plant, the heating and cooling demands from SYSTEMS are passed to the PLANT module that simulates the energy consumed by the plant to meet the SYSTEMS demands. The ECONOMICS module computes energy costs and is not used in this application.

Although DOE stopped all support for DOE-2 in 1999, White Box Technologies and others have continued to maintain and even add features to DOE-2.1E. For example, Huang [7] added an improved foundation model to the code at the request of the California Energy Commission (CEC). Once LBNL approves making DOE-2.1E open source, White Box Technologies intends to create an Open Source Center for Building Simulations to maintain the DOE-2.1E software for the community of building scientists and practitioners.

\subsubsection{AtticSim}

AtticSim is a computer tool for predicting the thermal performance of residential attics. The code is publicly available as an ASTM protocol [8]. It mathematically describes the conduction through the gables, eaves, roof deck, and ceiling; the convection at the exterior and interior surfaces; the radiant heat exchange between surfaces within the attic enclosure; the heat transfer to the ventilation air stream; and the latent heat effects due to sorption and desorption of moisture at the wood surfaces. Solar reflectance, thermal emittance, and water vapor permeance of the sundry surfaces are input. The model can account for different insulation R-values and/or radiant barriers attached to the various attic surfaces. It also has an algorithm for predicting the effect of air-conditioning ducts placed in the attic [9].

Typical construction places ductwork within the attic, which can triple the loads for the attic assembly for moderately leaky ducts [9][10]. Petrie [11] validated the duct algorithm in ASTM C 1340 against experimental data for an attic assembly tested first without and then with a radiant barrier attached to the underside of the roof deck. Validations showed the duct algorithm predicted the duct air change (inlet-tooutlet of the supply duct) within $\pm 0.3^{\circ} \mathrm{F}\left( \pm 0.2^{\circ} \mathrm{C}\right)$ over all tests housing an insulated duct system.

AtticSim was the subject of an extensive field validation conducted by Ober and Wilkes for ASHRAE [12], which provides mathematical documentation of the code and validation results for low-slope and steep-slope field data collected from seven different field sites. The code was later validated for steepslope asphalt shingle and stone-coated metal roofs [13]. AtticSim was also benchmarked against clay, 
concrete tile, painted metal roof, and attic assemblies incorporating above-sheathing ventilation (where heat in an inclined air space is carried by buoyant air away from the roof deck and out the roof ridge) [14].

\subsubsection{Integration of DOE-2/AtticSim}

DOE-2.1E and AtticSim are both written in FORTRAN and the method of integration primarily relies upon the idea of using the attic floor as a boundary condition for interaction between the two codes. For all simulations the attic floor is assumed sealed with no air leakage crossing from the conditioned space into the attic. The heat flows at the attic's roof, gables, eaves, and floor are calculated using the thermal response factor technique by Mitalas and Stephenson [15]. This method requires the thermal conductivity, specific heat, density, and thickness of each attic section for calculating conduction transfer functions. DOE-2.1E uses a similar technique of response factors (RF) [34] to calculate heat flows through the building envelope, but uses weighting factors (WF) to model the heat gain.

A response factor is a technique used in building energy simulations where the thermal response of a layer is characterized by pulsing the layer by a unit heat input on one side and recording the heat output on 1) the same side, 2) the other side, and by pulsing on the other side and recording the heat output on 3) the same side. When the ratio between the three time series stabilizes, the time series are truncated and replaced by a "Common Ratio". DOE-2.1E calculates a Common Ratio a few time steps (hours) earlier than does AtticSim. The impact of this on the results is judged to be very minor.

The initial incompatibility between the two sets of procedures and their setup for computing parallel path heat flows was a key hurdle for making AtticSim work seamlessly within the SYSTEMS module of the $D O E-2.1 E$ program. White Box Technology compared the response factors generated by $D O E-2.1 E$ to those used by AtticSim and found the differences to be relatively minor. Table 1 displays results for the stud section of a west-facing gable roof.

DOE-2.1E calculates the actual zone temperature using the TEMDEV subroutine in the SYSTEMS module that takes the heat flows into the Zone calculated by the LOADS module at an assumed fixed zone temperature, the heating or cooling input by the HVAC system based on the thermostat setting and HVAC system capacity, as well as the heat flows from mechanical or natural ventilation into the zone. In the integrated source code, the TEMDEV subroutine of $D O E-2.1 E$ has been replaced by AtticSim, which ignores all the heat flows that had been or would have been calculated by $D O E-2.1 E$ and calculates the attic air temperature through a detailed heat balance of the attic zone, including the heat gain or loss through the ducts if the HVAC was on the previous time step. For all other zones, the standard DOE$2.1 E$ procedure with the TEMDEV subroutine is used to derive their zone air temperature (as well as the heating or cooling input of the HVAC system). As SYSTEMS loops through the zones, it starts first with the attic, where it will invoke AtticSim, and pass to it inputs for the ambient conditions, thermal properties (response factors of the surfaces), the temperature of the space below, and the HVAC on-time from the previous time step. AtticSim then returns to $D O E-2.1 E$ the attic temperature, the heat flow through the ceiling, and the heat gain or loss to the HVAC ducts, which are used by $D O E-2.1 E$ to solve for the temperature of the zone below, the heat addition or removal, and finally energy consumption of the HVAC system. To ensure these changes didn't significantly affect the output of the integrated DOE2/AtticSim program, comparison studies found the differences to be negligible as shown in Table 1.

To affect this linkage, numerous changes were also necessary to the input processing doebdl program in order to pass the input data from the building model described in DOE-2's Building Description Language (BDL) to AtticSim. Some 20 new keywords have been added, in addition to the "data mining" of the existing $D O E-2$ inputs.

As stated AtticSim is an ASTM protocol [8] and is publicly available. It has been extensively peer reviewed and benchmarked against field data, and therefore was an excellent candidate for use with the 
whole building model. DOE-2 can be described as an "air heat balance" program, i.e., it only solves for the zone air temperature. Although incident solar radiation is considered using the "sol-air temperature" method, internal radiation exchange within a zone is ignored. Therefore, when DOE-2 models an attic, any radiation exchange due to the temperature differences between the underside of the roof and the top of the ceiling layers are not considered. The net effect of this modeling method is that $D O E-2$ cannot be expected to model accurately the impact of cool roof strategies where the amount of solar radiation entering the attic is changed. In such cases, $D O E-2$ does not adequately describe the radiation exchanges occurring in attics. AtticSim does not predict whole building performance. Combined, the two tools offer a powerful feature that can translate reduced heat flux from cool roof and attic technologies to annual energy and cost savings in a way that can be benchmarked against demonstration homes.

Table 1. Sample Output from $D O E-2.1 E$ and AtticSim for the response factors computed through the stud path in the gable end of an attic.

\begin{tabular}{|r|r|r|r|}
\hline Attic Surface & \multicolumn{3}{c|}{ DOE-2.1E Response Factors } \\
\hline West_facing_gable_stud_path & & & \\
0 & 0.0725388229 & 0.0098278262 & 0.9016193748 \\
1 & -0.0203016642 & 0.0267347004 & -0.6602395177 \\
2 & -0.0007713751 & 0.0100655956 & -0.1315478235 \\
3 & -0.0002378091 & 0.0031069645 & -0.0405923724 \\
\hline 4 & & & \\
\hline COMMON_RATIO & 0.3085973561 & & \\
\hline Attic Surface & AtticSim Response Factors & \\
\hline West_facing_gable_stud_path & & & \\
\hline 0 & 0.0725388265 & 0.0098278265 & 0.9016194031 \\
\hline 1 & -0.0203016643 & 0.0267347006 & -0.6602395663 \\
\hline 2 & -0.0007713751 & 0.0100655958 & -0.1315478232 \\
\hline 3 & -0.0002378091 & 0.0031069647 & -0.0405923734 \\
\hline 4 & -0.0000733872 & 0.0009588012 & -0.0125266982 \\
\hline COMMON_RATIO & 0.3085973437 & & \\
\hline & Differences between DOE-2.1E and AtticSim \\
\hline 0 & 0.000000004 & 0.000000000 & 0.000000028 \\
\hline 1 & 0.000000000 & 0.000000000 & -0.000000049 \\
\hline 2 & 0.000000000 & 0.000000000 & 0.000000000 \\
\hline 3 & 0.000000000 & 0.000000000 & -0.000000001 \\
\hline 4 & -0.000073387 & 0.000958801 & -0.012526698 \\
\hline & -0.000000012 & & \\
\hline
\end{tabular}

\subsection{WEB INTERFACE}

\subsubsection{Building Templates}

For the web-based Roofing Savings Calculator, template files have been created for four building input types - residential, medium-sized office, warehouse, and big box retail store. These building types constitute the 4 most prevalent building types by conditioned floor area or number of buildings in the United States [35]. The residential template file is adapted from the template file developed by Huang [16] for the RESFEN program, a similarly easy-to-use program for calculating window energy performance using $D O E-2.1 E$ as the simulation engine. The three commercial template files are adapted from a set of commercial building prototypes first developed by Huang in 1990 [16] that later served as basis for DOE's commercial building benchmark models [17].

These are called template files because they contain numerous macros, a feature available in $D O E-2$ since the early 1990s, that allows the file to be altered. This is used to modify a single file based on high-level user inputs, such as those defined by a user's selection in the web-based Graphical User Interface (GUI), so that a specific building file can be derived and is formatted properly for processing by the simulation engine. These high-level inputs include building location, vintage, floor area, number of floors, ratio of window area to floor area (residential) or window area to wall area (commercial), and HVAC equipment 
specifications. For the RSC, the user inputs are much more specific for the attic/roof assembly, including the roof construction, roof covering material, roof slope/inclination, solar reflectance, thermal emittance, inclusion of radiant barrier, HVAC duct location and characteristics, and nominal R-value of the ceiling. Once these user inputs have been defined, the macro statements allow the template file to be modified accordingly.

\subsubsection{Web Deployment}

An important objective identified early in development was to maximize project impact by providing a publicly and freely accessible website for comparative simulations of traditional and energy-saving roofing options. This web portal is designed to serve as an industry-consensus roof savings calculator for commercial and residential buildings using whole-building energy simulations. Many current web technologies were employed in the development of the deployed calculator. The use of dynamic hypertext markup language (DHTML) includes technologies such as HTML and the HTML Document Object Model (HTML DOM) [18], cascading style sheets (CSS) [19], asynchronous JavaScript and eXtensible Markup Language (AJAX), and the Personal Home Page language (PHP) [20], as well as the jQuery [21] and jQuery User Interface (jQueryUI) Javascript libraries. These dynamic capabilities allow for an interface that enhance intuitiveness, simplifies required input by adaptively asking only necessary items, and minimizes cognitive load required for quickly defining parameters of interest.

\section{BENCHMARKING}

The 2003 F.W. Dodge [22] report shows tile roofs comprise $~ 30 \%$ of the new and retrofit roof markets in California. We therefore conducted field experiments in Southern California to benchmark both AtticSim as a stand-alone tool and the new RSC tool. AtticSim has a history of validations against several different profiles of tile, stone-coated metal, asphalt shingle and standing seam metal roofs, all of which were field tested at ORNL. However, AtticSim was also benchmarked against two of the Ft. Irwin homes to assist White Box Technology with its benchmark of the RSC tool.

The four demonstration homes were configured for making two bases of comparison: 1) concrete tile applied directly to the deck - one coated with a cool color coating, the other not coated; and 2) concrete tile elevated 11/2-in $(0.038-\mathrm{m})$ above the deck using double battens and ventilated via eave and ridge vents-one roof coated with a cool color coating, the other not coated. AtticSim was benchmarked against House N5 for summer data (Aug. 2008) and House N8 for winter data (Feb. 2008). During these periods tenants were paid a $\$ 200$ per month incentive to keep their thermostats at $72^{\circ} \mathrm{F}\left(22.2^{\circ} \mathrm{C}\right)$. House N5 has the tile attached directly to the deck (labeled D-t-D) with the tile painted with COOLTILE IR COATINGS ${ }^{\mathrm{TM}}$ by American RoofTile Coatings. House N8 had conventionally painted tile placed on double battens (labeled DB), also known as counter-battens, in which the first layer of battens runs upslope and the second runs cross slope and parallel to the ridge of the roof.

Heat flux transducers (HFTs) were attached to the roof sheathing to measure the heat flux crossing the north- and south-facing roof decks. The contractor insulated the attic floor with R-38 (RSI-6.7) fiberglass batt. We opted to use Type T thermocouples placed across the insulation at 3 different ceiling locations and were used to reduce the ceiling heat flux from the product of thermal conductivity of the batt and temperature difference across the batt. Samples of the R-38 (RSI-6.7) batt insulation were retrieved from the demonstration site and measured for thermal conductivity in ORNL's heat flow metering apparatus. Prior experience showed the HTFs sensitivity too low for accurately measuring the flux across R-38 (RSI6.7 batt). 


\subsection{ATTICSIM BENCHMARK OF HOUSE N5}

Pyranometers were attached to the north- and south-facing roof surfaces to measure the global irradiance on the respective sloped surface. Outdoor air temperature and relative humidity (measured under the soffits of the north- and south-facing exterior walls) and indoor air temperature (measured at the thermostat) were used as boundary conditions by AtticSim. The code computed the surface temperature of the tile, the air temperature in the inclined air space made by the tile, the heat flux crossing the roof decks, the attic air temperature, and the heat flux crossing the attic floor.

Estimates had to be made of the airflow induced by a solar powered attic ventilation fanstalled on the south facing roof. All homes had these fans that energized whenever the photovoltaic panel generated enough current to drive the fan. The heat flux crossing the south facing roof deck was accurately computed by AtticSim as compared to the flux measured by the HFTsinstalled on underside of roof deck, Figure 5. Benchmarks for the attic floor (Figure 6) show the AtticSim predictions lead the measured flux about 2 hours. Results show a thermal capacitance effect between the measured flux reduced from thermometry and AtticSim predictions. The shift is most evident during periods of peak irradiance. However, measurement and prediction are in better agreement during the late evening and early morning hours, Figure 6.

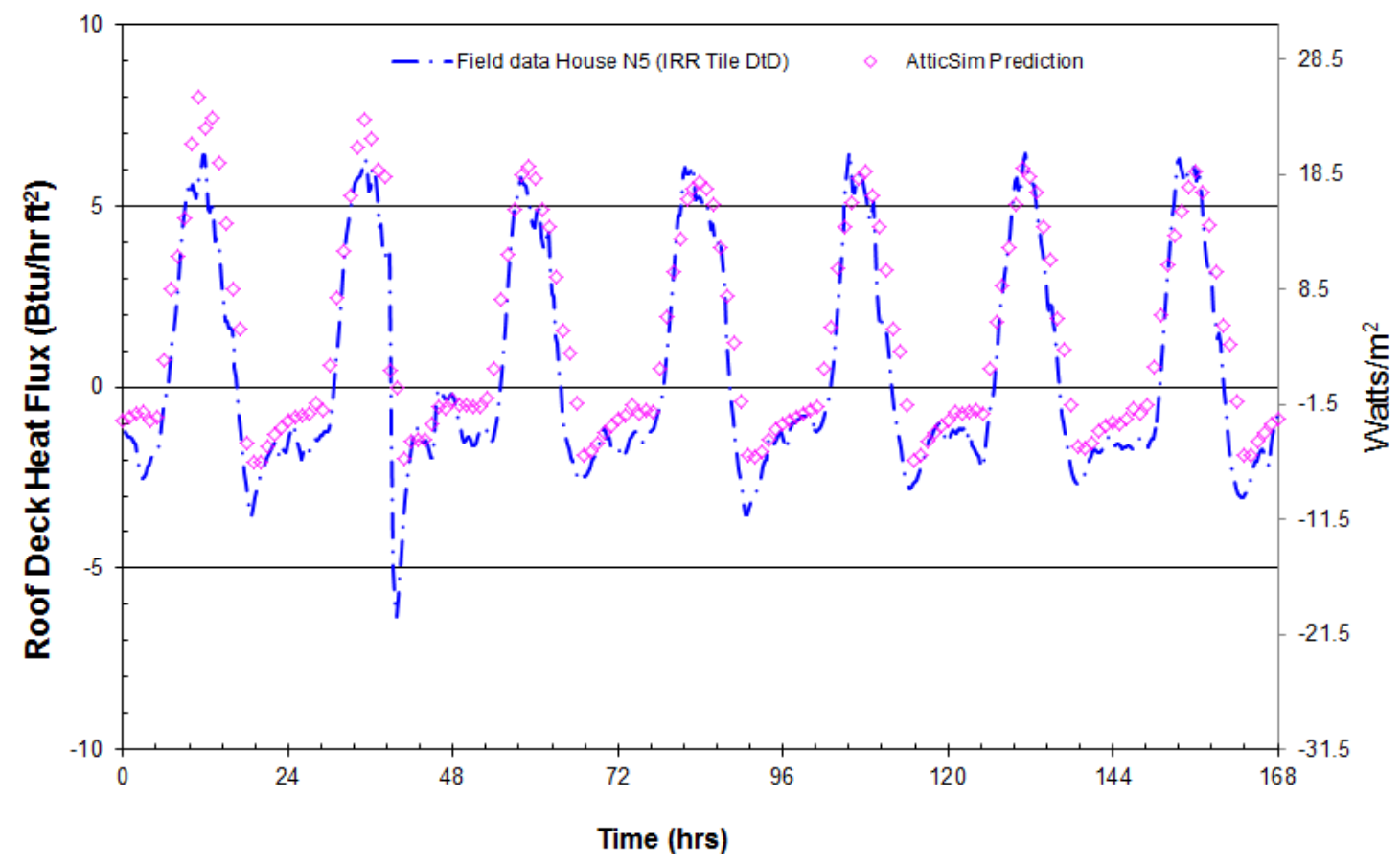

Figure 5. The heat flux through the south-facing roof deck for House N5 having cool color tile laid directly to the deck. 


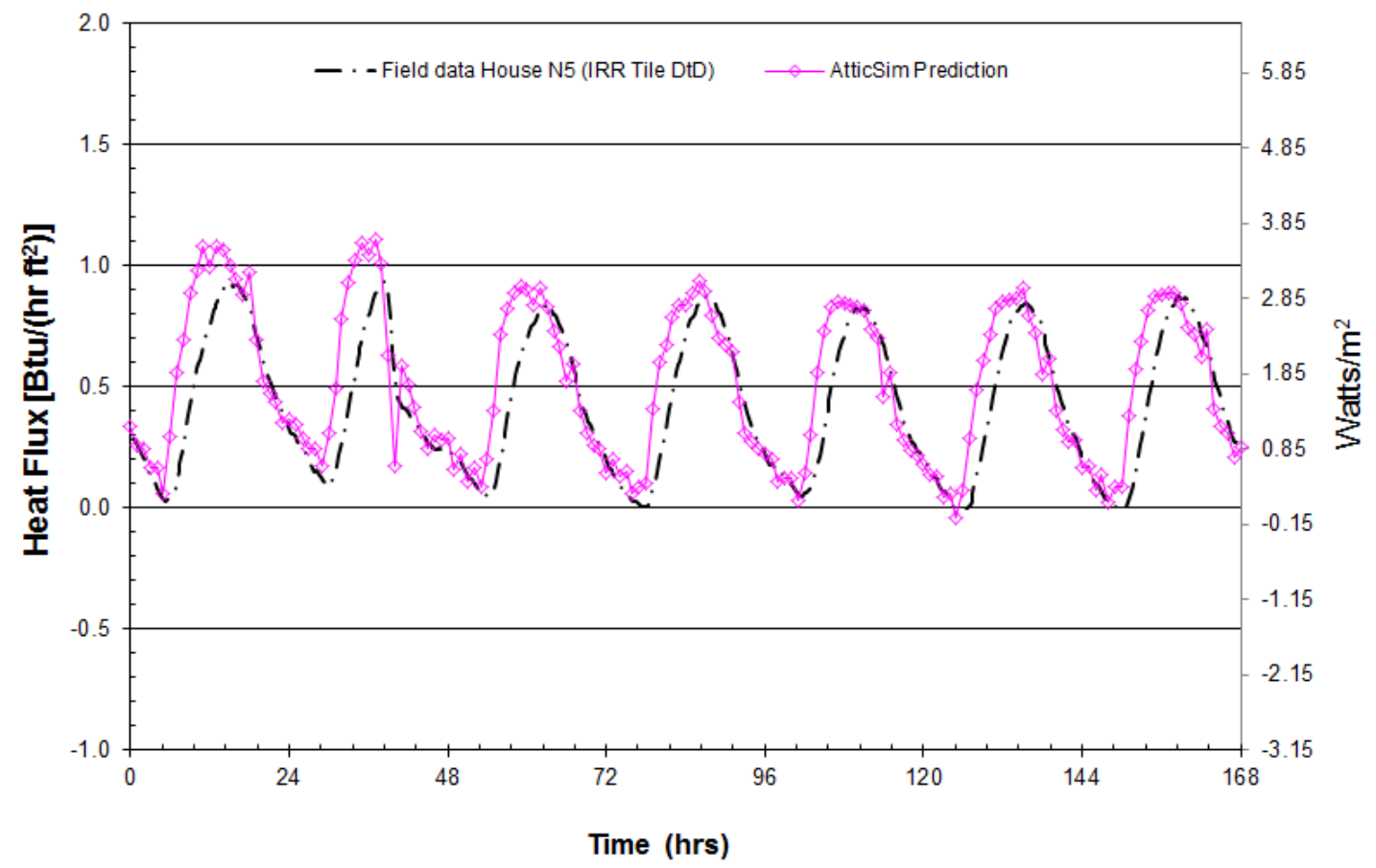

Figure 6. The heat flux across the attic floor for House N5 having cool color tile laid directly to the deck.

\subsection{ATTICSIM BENCHMARK OF HOUSE N8}

The air temperature in the inclined air space formed by the double batten arrangement of the concrete tile is shown in Figure 7 and Figure 8 for data collected during February 2008. The code replicated the measured air temperature in the ventilated space under the tile very well. Miller et al. [13] provide details of the energy balance that is used to compute the air temperature in the air space. 


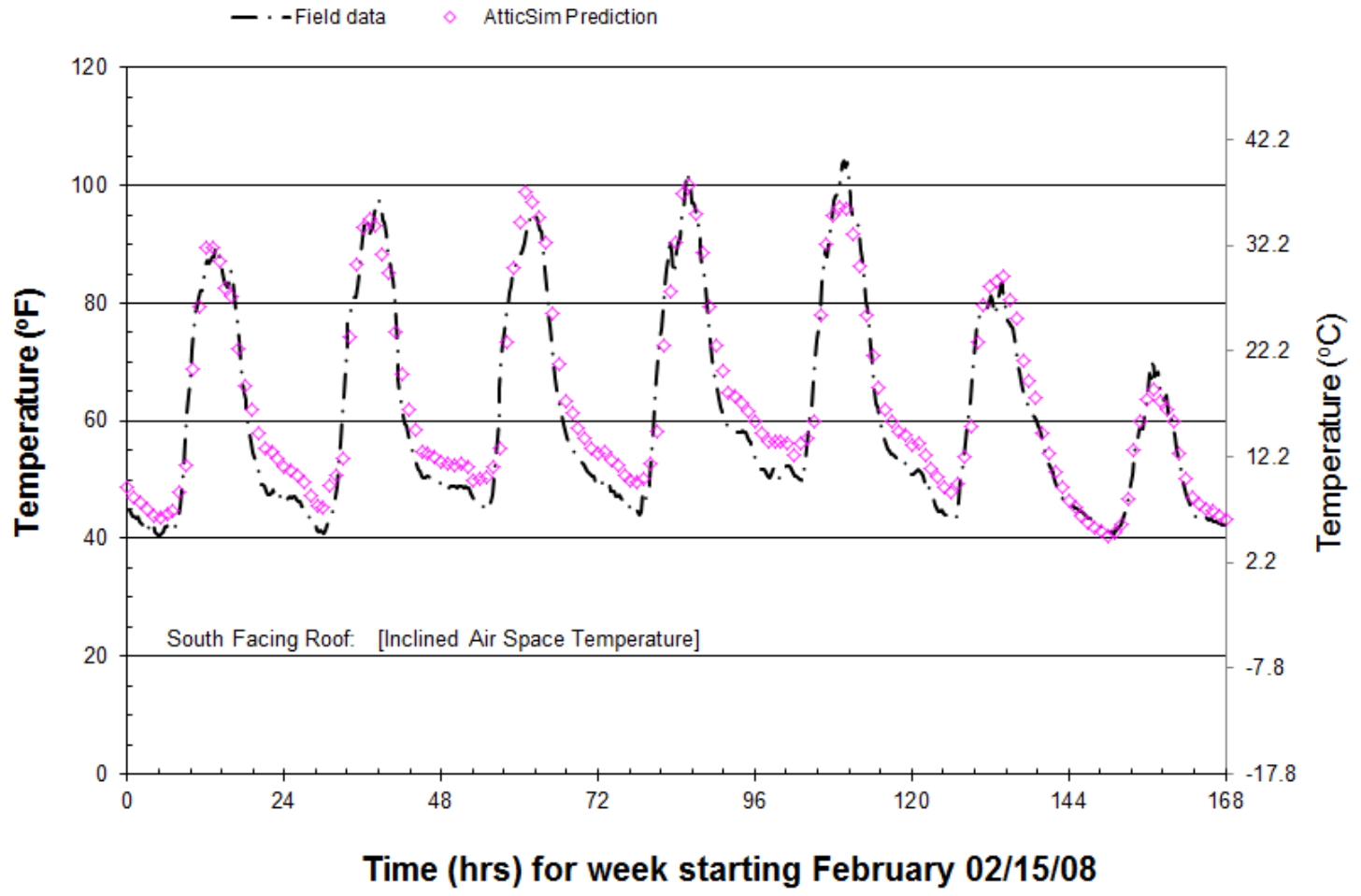

Figure 7. The air temperature in the inclined air space under the concrete tile is predicted to within $\pm 2^{\circ} \mathrm{F}\left(0.6^{\circ} \mathrm{C}\right) 0$ of the field data for House N8 having conventionally painted tile placed on double battens.

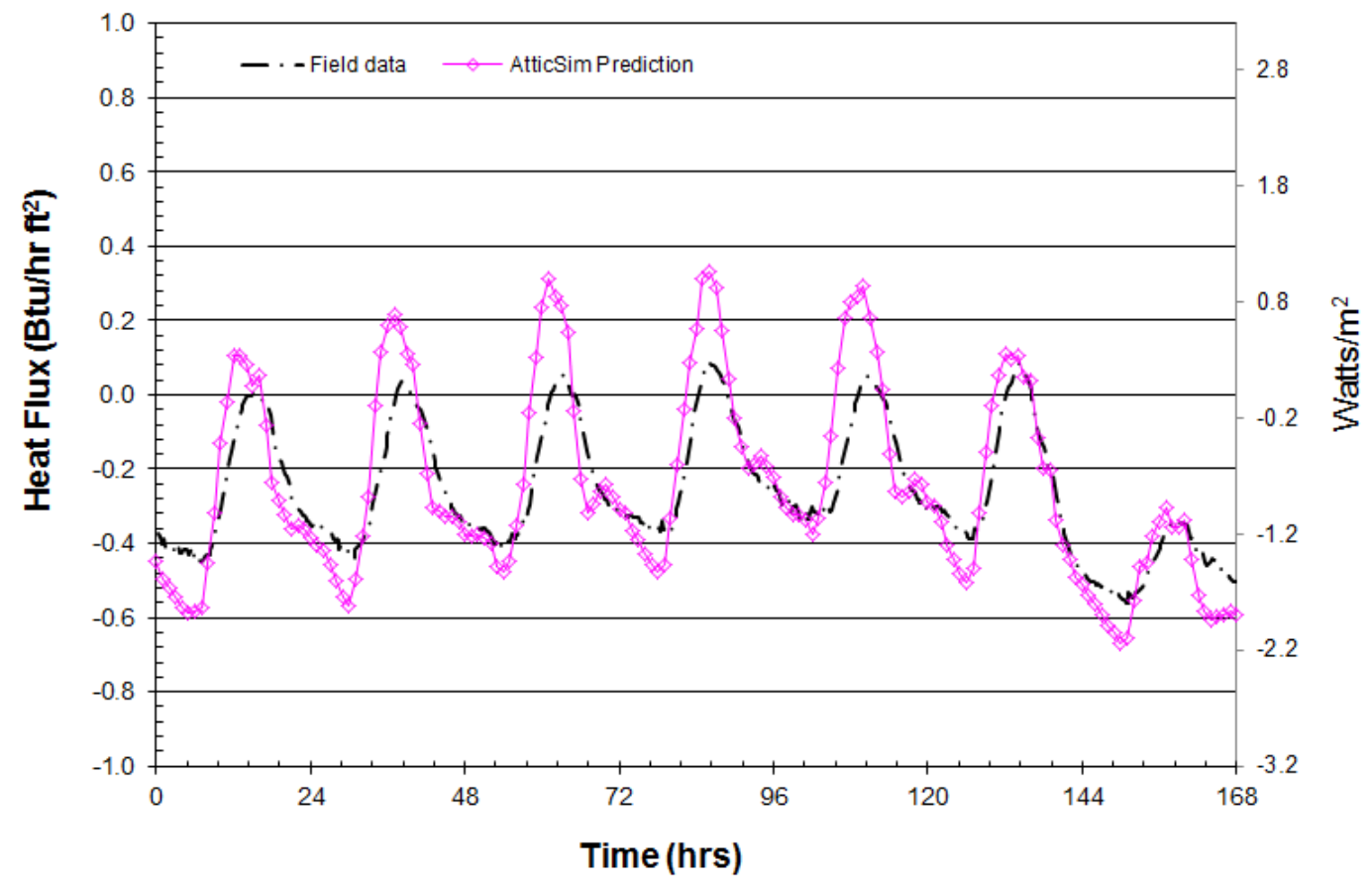

Figure 8. The ceiling heat flux computed by AtticSim and benchmarked against the field data for House N8 having conventionally painted tile placed on double battens. Data collected Feb. 2008. 
For this February week of data, the outdoor air temperature peaks at about $68^{\circ} \mathrm{F}\left(20^{\circ} \mathrm{C}\right)$ during the day and drops to about 40 to $50^{\circ} \mathrm{F}\left(4.4\right.$ to $\left.10^{\circ} \mathrm{C}\right)$ at night. Therefore, the ceiling heat loads are relatively small and did not exceed $\pm 0.5 \mathrm{Btu} /\left(\mathrm{hr} \mathrm{ft}^{2}\right)$ [0.16 W/m2]. Figure 7 shows AtticSim simulated the daily trends in ceiling heat flux the daytime trends in ceiling heat flux within about $0.3 \mathrm{Btu} /\left(\mathrm{hr} \mathrm{ft}^{2}\right)$ while the nighttime heat flux predictions are more accurate, as shown in Figure 8. This occurs because the temperature difference across the R- 38 (RSI 6.7) batt insulation is at best only $3.6^{\circ} \mathrm{F}\left(2^{\circ} \mathrm{C}\right)$ during the day, while at night the temperature drop across the ceiling insulation is about $14.4^{\circ} \mathrm{F}\left(8^{\circ} \mathrm{C}\right)$. Therefore, the error is primarily due to the uncertainty of the temperature measurements used for computing the heat flux. Heat flux was calculated using temperature difference, so this finding is only valid for steady-state conditions, not transient conditions.

\subsection{DOE-2.1E/ATTICSIM BENCHMARK HOUSES}

We repeated the simulations described above for House N5 using the August 08 week of field data and for House N8 using the February 08 data with the combined DOE-2.1E/AtticSim code. Testing determined whether AtticSim worked properly as a subroutine within DOE-2.1E for the thermal exchange through the attic floor (i.e., house ceiling) and for the data exchange about HVAC operations and duct losses. Both of these issues are complex, since they are nonlinear as well as interrelated. The heat flows through the attic floor, which are critical for determining the energy savings from attic conservation measures, are further complicated by the fact that $D O E-2$ uses several sequential steps to derive net zone heat flows, so that in coupling DOE-2 with AtticSim it has been necessary to disable some of these steps to prevent double counting. To calculate the duct losses, AtticSim needs to know the on-time for the HVAC system, but that is not known until further into the simulation process. Ultimately, it was found necessary to model the attic twice, once with DOE-2 and then again with AtticSim.

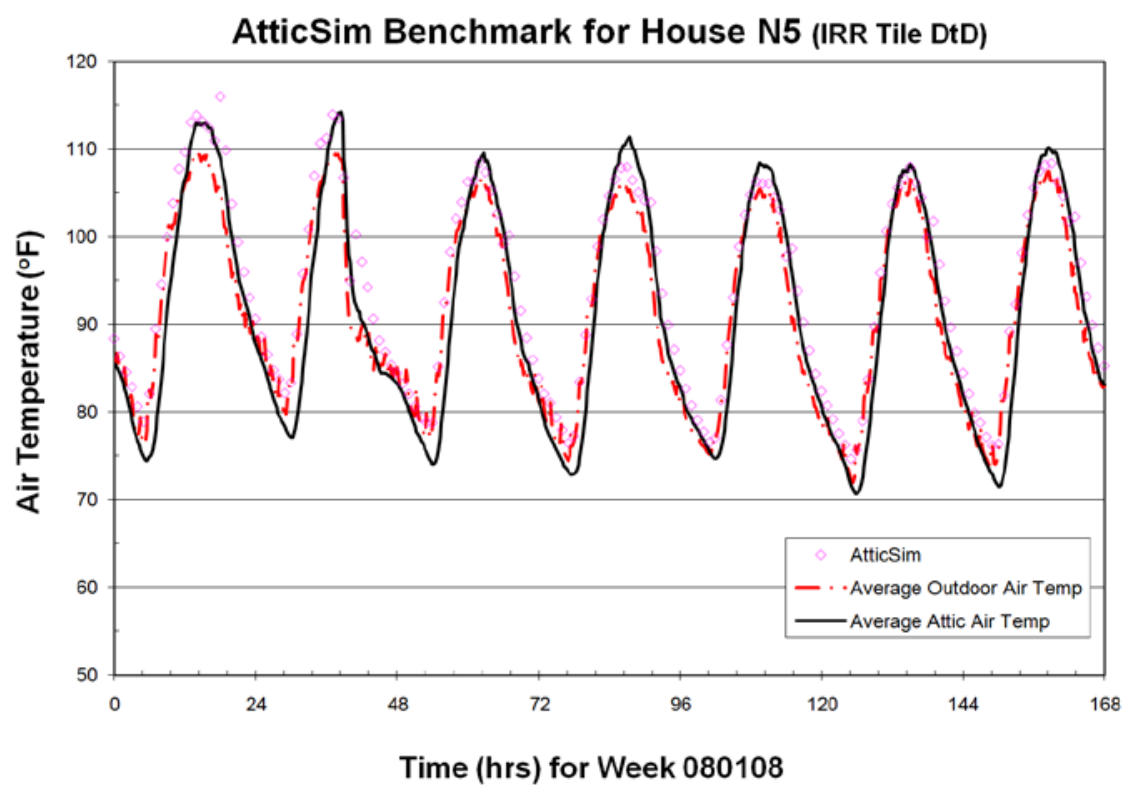

Figure 9. Comparison of DOE-2.1E/AtticSim to measured attic temperature for House N5 collected August '08. 
Figure 9 shows the field measured attic air temperatures benchmarked against the modeled air temperature computed from the DOE-2/AtticSim program and computed from the stand-alone AtticSim code. Both codes predict the field measurements within $\pm 2^{\circ} \mathrm{F}\left(1.1^{\circ} \mathrm{C}\right)$ with exception of the early morning hours from about 2am till 8am. The results of the benchmark show that the DOE-2/AtticSim program is predicting the attic air temperature to about the same accuracy as the standalone AtticSim code. Hence the integration of AtticSim into the DOE-2 code appears to be working adequately.

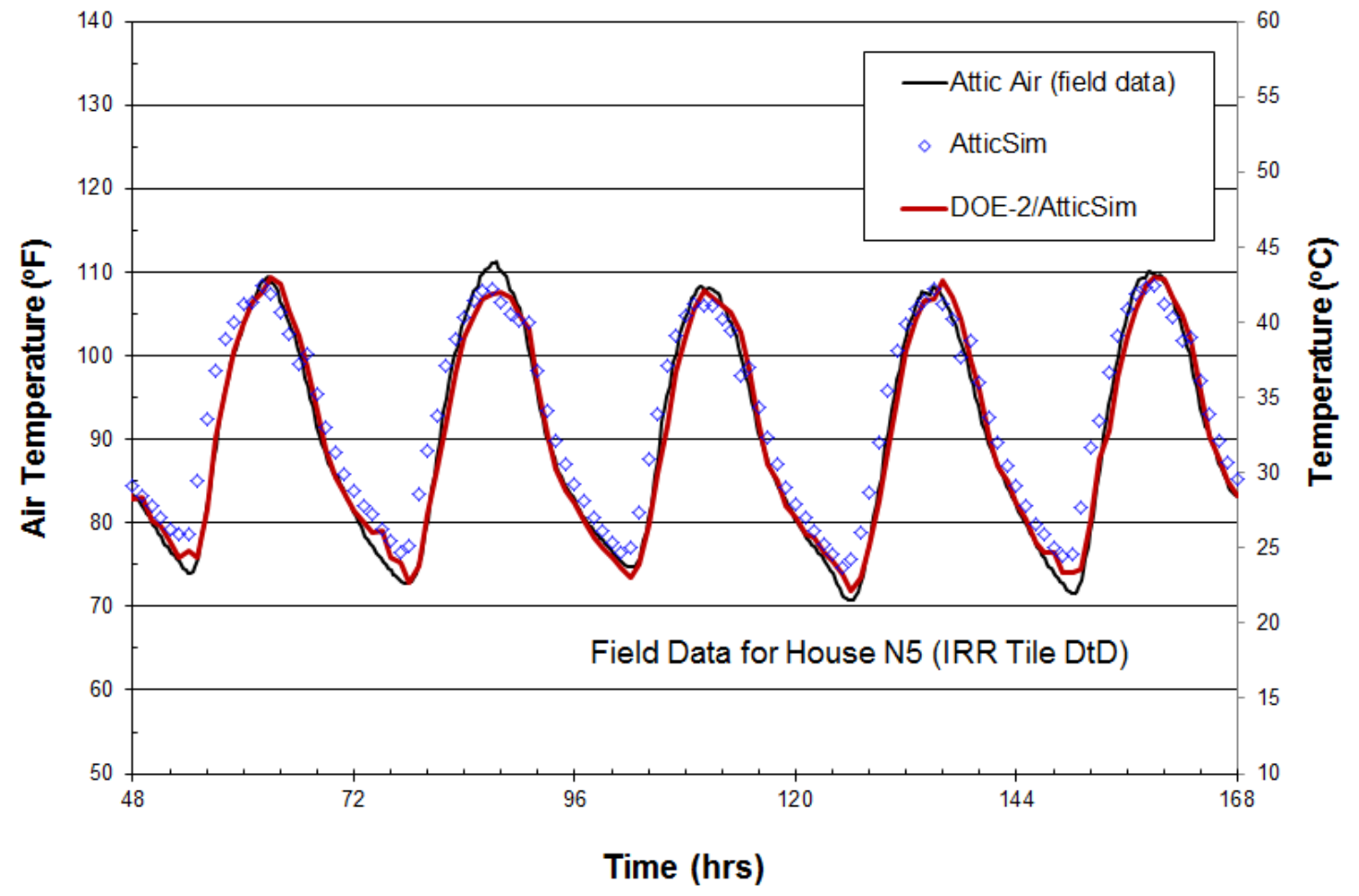

Figure 10. Comparison of AtticSim before and after integration with DOE-2.

\section{ROOF SAVINGS CALCULATOR VALIDATION}

\subsection{BACKGROUND}

From 2009-2011, the contractor (White Box Technologies) worked with the Oak Ridge National Laboratory (ORNL) program manager to create the Roof Savings Calculator (RSC), an easy-to-use Webbased calculator for estimating the energy impacts from various roof and attic strategies on the heating and cooling energy use of four building types—residential, office, retail, and warehouse—in 239 U.S. locations. The contractor's main responsibility in that project was to develop a custom program, doe2attic, for simulating roofs and attics by linking the DOE-2.1E (doesim) whole-building simulation program with ORNL's AtticSim program. The RSC has been planned to be an industry-consensus energy-savings calculator that companies and national laboratories can use to promote the energy benefits of cool roofing products. After the initial roll-out of the RSC in mid-2011, questions were raised because the results produced by the RSC for "cool roofs" had some differences from previous studies, especially those reported by LBNL. While the RSC calculated cooling savings were similar to those from previous LBNL 
studies, it also calculated significant penalties during the heating season, which the LBNL studies showed to be very small.

The purpose of this project is to validate the RSC in two ways. First, conduct a thorough comparison of the computer simulations behind the RSC (doe2attic), against three other simulation programs EnergyPlus, DOE-2.1E, and MicroPas. EnergyPlus is a whole-building simulation program currently supported by DOE, while DOE-2.1E and MicroPas were used in the previous LBNL studies for roofs in commercial and residential buildings, respectively. Second, compare the same four programs to detailed measured data from an experimental facility operated by ORNL in South Carolina where different segments of the attic had different roof and attic systems.

\subsection{COMPARISON OF RSC TO PREVIOUS LBNL STUDIES}

After the RSC went online on April 22, 2010, LBNL's Heat Island Group used it to estimate the energy savings from cool roofs in residential buildings in various California climates and in commercial buildings (medium-sized office) in various US climates. They found that, in comparison to earlier studies done at LBNL[23][24][25], the cooling savings were within 15\% of each other, but the heating penalties were 6-12 times larger in the RSC (Figure 11 and Figure 12). It should be noted that this discrepancy is in part due to the fact that the heating penalties in the previous LBNL studies were small in absolute terms but a large percentage in relative terms. The $R S C$ showed average heating penalties to be up to $60 \%$ of the cooling savings, the LBNL study showed them to be $5 \%$.

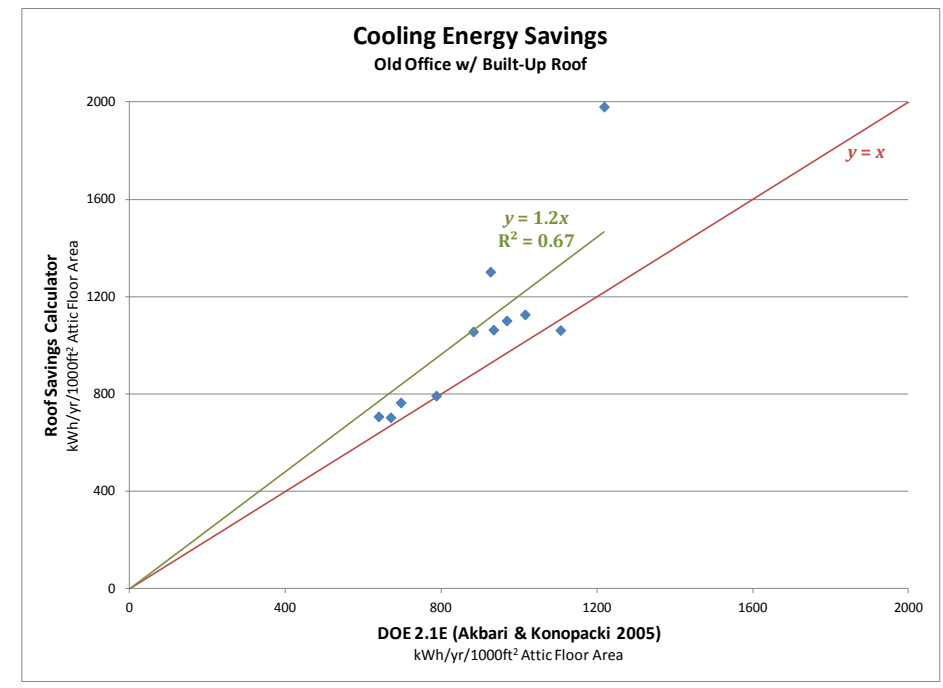

Figure 11. RSC and LBNL Cooling Energy Savings from Cool Roofs (LBNL 2012) 


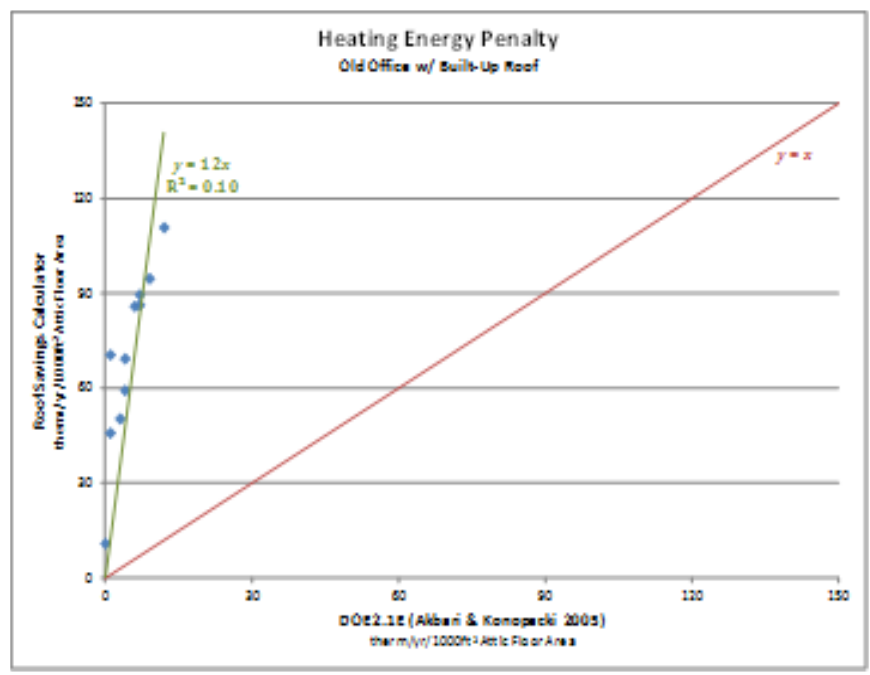

Figure 12. RSC and LBNL Heating Energy Penalties from Cool Roofs (LBNL 2012)

The difficulty with this discrepancy is that, whereas LBNL's previous study showed that cool roofs were beneficial in all 14 US climates studied, the RSC now showed them to be detrimental in colder locations such as Chicago, New York, Philadelphia, and Baltimore as shown in Figure 13. It also appears that the $R S C$ shows greater sensitivity to the energy impacts due to cool roof changes in general, since the RSC shows larger cooling savings in hot locations such as Phoenix.

The preliminary assessment of this difference in heating penalties between the $R S C$ and the previous LBNL studies is that it's due to differences between how the DOE-2.1E program used in Akbari \& Konopacki 2005a, 2005b and AtticSim account for radiant heat exchange in interior spaces. The later LBNL study by Akbari et al. 2006 used the MicroPas program and showed a similar difference in heating penalties, but those results are not evaluated in this preliminary assessment as they are part of the scope for planned work.

Since doe2attic is a modified version of $D O E-2.1 E$ where the attic model has been replaced by AtticSim, the BDL input files generated by RSC are compatible with either doe2attic or DOE-2.1E. In the preliminary assessment, WBT obtained the RSC input files for a set of 40 test runs performed by LBNL and modified them to run with either doezattic or the original DOE-2.1E program. To narrow down the cause for the discrepancy, the attic model was progressively simplified by eliminating the duct model and attic ventilation, so that what remained was a simple model of an unvented attic with no interaction with the HVAC system. However, when this model was run through doe2attic and DOE-2.1E, the difference in heating penalties was reduced, but still significant with doe2attic showing double the heating penalties as shown by $D O E-2.1 E$ (Table 5). It is anticipated that the duct system and attic ventilation function as scalar factors that multiply cooling savings and heating penalties, but not affect their relative magnitudes. 


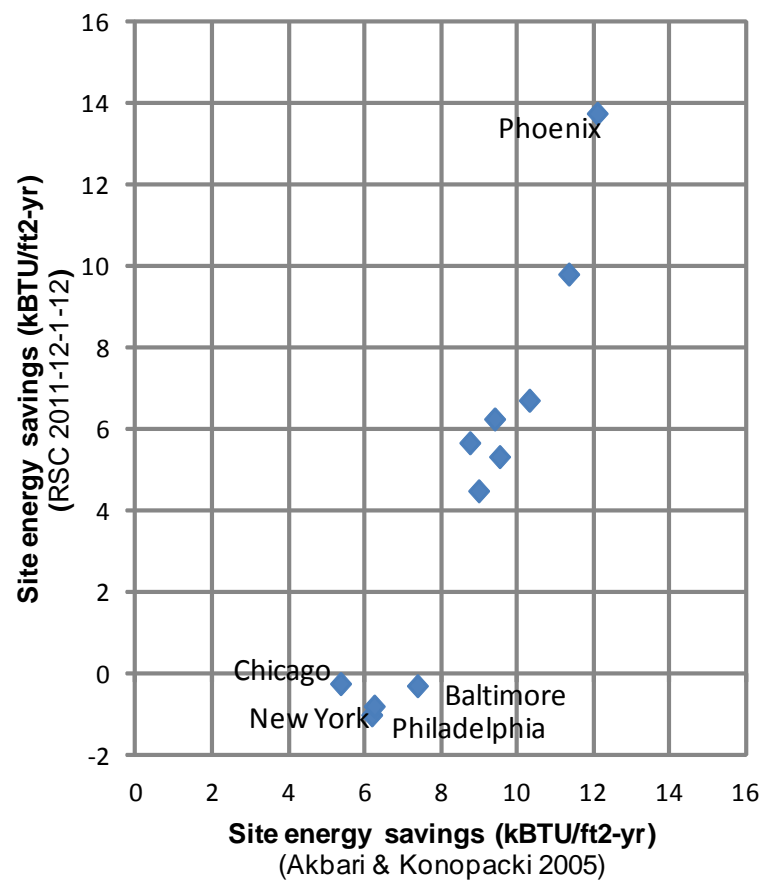

Figure 13. Comparison of net energy savings from cool roofs between

Table 2. Comparison of test simulations of the same attic model using DOE-2.1E, doe2attic, and EnergyPlus

\begin{tabular}{|c|c|c|c|c|c|c|c|c|c|c|c|c|c|c|c|c|c|c|}
\hline \multirow[b]{3}{*}{ Location } & \multicolumn{6}{|c|}{ DOE-2.1E unmodified } & \multicolumn{6}{|c|}{ DOE-2.1E + AtticSim (doe2attic) } & \multicolumn{6}{|c|}{ EnergyPlus V7.0 } \\
\hline & \multirow{2}{*}{\begin{tabular}{|l} 
Heat \\
MBTU
\end{tabular}} & \multicolumn{2}{|c|}{ Heat penalty } & \multirow{2}{*}{$\begin{array}{l}\text { Cool } \\
\text { kWh }\end{array}$} & \multicolumn{2}{|c|}{ Cool savings } & \multirow{2}{*}{$\begin{array}{l}\text { Heat } \\
\text { MBTU }\end{array}$} & \multicolumn{2}{|c|}{ Heat penalty } & \multirow{2}{*}{$\begin{array}{l}\text { Cool } \\
\mathrm{kWh}\end{array}$} & \multicolumn{2}{|c|}{ Cool savings } & \multirow{2}{*}{$\begin{array}{l}\text { Heat } \\
\text { MBTU }\end{array}$} & \multicolumn{2}{|c|}{ Heat penalty } & \multirow{2}{*}{$\begin{array}{l}\text { Cool } \\
\mathrm{kWh}\end{array}$} & \multicolumn{2}{|c|}{ Cool savings } \\
\hline & & MBTU & $\%$ & & kWh & $\%$ & & MBTU & $\%$ & & $\mathrm{kWh}$ & $\%$ & & MBTU & $\%$ & & kWh & $\%$ \\
\hline Miami & 7.4 & 0.1 & 1 & 31673 & 802 & 3 & 7.3 & 0.1 & 1 & 32576 & 1432 & 4 & 0.3 & 0.1 & 41 & 29726 & 1533 & 5 \\
\hline Los-Angeles & 15.4 & 1.5 & 10 & 10623 & 894 & 8 & 14.3 & 2.5 & 18 & 11573 & 1639 & 14 & 6.7 & 2.3 & 34 & 12442 & 1509 & 12 \\
\hline Phoenix & 21.5 & 2.3 & 11 & 29133 & 1538 & 5 & 20.5 & 3.9 & 19 & 29868 & 2586 & 9 & 9.6 & 2.2 & 22 & 27218 & 2118 & 8 \\
\hline New-Orleans & 28.1 & 1.7 & 6 & 22116 & 849 & 4 & 26.4 & 2.8 & 11 & 22881 & 1391 & 6 & 9.6 & 1.8 & 19 & 21931 & 1456 & 7 \\
\hline Houston & 32.5 & 1.8 & 6 & 23154 & 801 & 4 & 30.3 & 2.9 & 10 & 23970 & 1392 & 6 & 13.6 & 1.7 & 12 & 22729 & 1415 & 6 \\
\hline Fort-Worth & 52.5 & 2.5 & 5 & 19973 & 759 & 4 & 49.8 & 4.5 & 9 & 20702 & 1331 & 6 & 21.3 & 2.9 & 14 & 20147 & 1449 & 7 \\
\hline Atlanta & 77.3 & 3.6 & 5 & 15308 & 831 & 5 & 73.9 & 6.2 & 8 & 16088 & 1416 & 9 & 35.6 & 3.9 & 11 & 15696 & 1325 & 8 \\
\hline Baltimore & 94.4 & 3.5 & 4 & 12575 & 634 & 5 & 90.7 & 6.2 & 7 & 13165 & 1111 & 8 & 44.2 & 4.8 & 11 & 13053 & 1140 & 9 \\
\hline New-York & 104.6 & 3.0 & 3 & 11198 & 519 & 5 & 100.9 & 5.7 & 6 & 11792 & 959 & 8 & 40.2 & 4.1 & 10 & 12316 & 1108 & 9 \\
\hline Philadelphia & 106.5 & 3.6 & 3 & 11729 & 592 & 5 & 102.7 & 6.3 & 6 & 12310 & 1033 & 8 & 51.7 & 4.9 & 10 & 12125 & 1043 & 9 \\
\hline Chicago & 141.9 & 3.9 & 3 & 10188 & 573 & 6 & 136.8 & 6.8 & 5 & 10740 & 1006 & 9 & 66.8 & 6.0 & 9 & 10852 & 1017 & 9 \\
\hline
\end{tabular}

LBNL 2005 study and the RSC (data from LBNL 2012)

From an algorithmic perspective, the differences in the attic model of DOE-2.1E and doe2attic are easy to explain. doe2attic uses AtticSim, which contains a detailed heat balance solution for the attic heat flows taking into account radiation, convection, and conduction. The room model in DOE-2.1E, however, uses a weighting factor method to derive the room air temperature, with no explicit solution of the interzone radiative transfer between different room surfaces, such as between the bottom of the roof and the top of the ceiling. Heat flows through the ceiling is calculated as pure conduction between the air temperatures of the attic and the space below. Therefore, in DOE-2.1E the only possible impact of a cool roof on heating and cooling loads is by lowering the attic air temperature. However, in doe2attic there is also the impact of a cool roof in reducing the radiative heat transfer between the roof and the top of the ceiling. This difference can be seen in Table 5, where doe2attic produces higher cooling savings as well as heating penalties than does the unmodified $D O E-2.1 E$ program. 
Akbari and Levinson [36] states the DOE-2.1E runs presented in Akbari \& Konopacki 2005 [23] included a function that used accounted for the intrazone radiant heat transfer. However, the results for DOE-2.1E unmodified in Table 5 are similar to those reported in Akbari \& Konopacki 2005 [24]. A backup of raw data from Steve Konopacki's work, believed to include the simulation and data files used for this 2005 study, was analyzed to attempt to identify the appropriate files, resolve the extent of modeling used by the Gartland model, and reconcile the similarity with the DOE-2.1E unmodified runs which have no radiant barrier. Upon further analysis, it was concluded from the original simulation files that the previous study's simulations did not use the Gartland function or any other to model the radiation heat transfer in the attic. There is also no documentation of how Micropas models intrazone radiant heat transfer. Ken Nittler, author of Micropas, has conveyed that the simulation runs performed for Akbari et al. [23] used a preliminary version of Bruce Wilcox’s UZM (Unconditioned Zone Model).

Another check of this explanation for why $D O E-2.1 E$ and doe2attic heating penalties differ was provided by converting the RSC input files to EnergyPlus (a geometry discrepancy in the resulting EnergyPlus file was rectified for this simulation), which also uses the same heat balance method as doe2attic to solve for the room heat flows. These results appear in the columns on the right of Table 5 . Base heating energies calculated by EnergyPlus were less than half those calculated by doe2attic (which is really DOE-2.1E for the house below the attic). However, the percent heating penalties agreed quite well with doe2attic and not with $D O E-2.1 E$ (Figure 14). There is debate as to which metric to consider since increasing roof albedo changes cooling and heating loads by amounts proportional to the change in roof solar heat gain, rather than proportional to the base cooling or heating loads.

$\%$ Heating Penalties

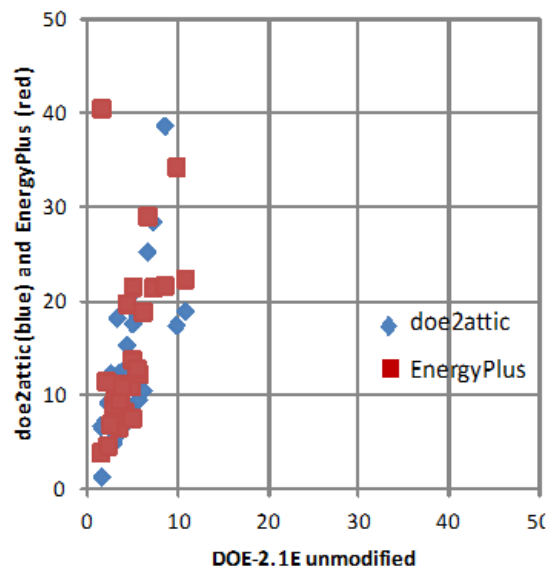

\% Cooling Savings

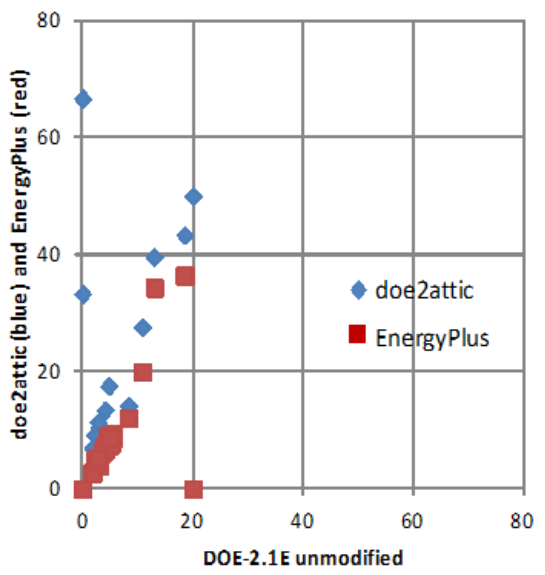

Figure 14. Percent heating penalties and cooling savings calculated by EnergyPlus and doe2attic compared to unmodified DOE-2.1E

The convective coefficient governing heat transfer from attic ceiling to attic air can be greater in winter than in summer. In winter, warm air rises from the attic floor, is cooled by the attic ceiling, falls to the floor, and thus creates a natural convection loop. In summer, the attic ceiling is warmer than the attic floor, and there is minimal natural convection.

To determine the magnitude of radiative heat transfer between the roof and the ceiling, WBT used a littleknown feature in $D O E-2.1 E$ that performs a heat balance in reverse to compute the temperatures of all interior surfaces [26]. Once these temperatures are known, a simple spreadsheet assuming infinite parallel planes was used to calculate the radiative heat transfer between the under surface of the roof and the top surface of the ceiling based on their temperature difference for every hour of the $D O E-2.1 E$ simulations: 


$$
\begin{gathered}
\mathrm{Q}_{\text {rad }}=\left(1 / \varepsilon_{1}+1 / \varepsilon_{2}-1\right)\left(\mathrm{T}_{\text {roof }}{ }^{4}-\mathrm{T}_{\text {ceil }}{ }^{4}\right) * \mathrm{~A}_{\text {ceil }} \\
\text { where } \varepsilon_{1}, \varepsilon_{2}=\text { emissivity of roof underside and ceiling top } \\
\sigma=\text { Stefan-Boltzmann constant }
\end{gathered}
$$

The convective heat transfer to the space below due to this additional radiative heat is calculated as:

$$
\begin{aligned}
\mathrm{Q}_{\text {to_space }}=\mathrm{Q}_{\text {rad }} *\left(\mathrm{U}_{\text {ceil }} /\left(\mathrm{U}_{\text {ceil }}+\mathrm{U}_{\text {cond }}\right)\right) & \\
\text { where } \mathrm{U}_{\text {ceil }} & =\text { conductance of ceiling layer } \\
\mathrm{U}_{\text {cond }} & =\text { convective heat transfer coefficient }
\end{aligned}
$$

This equation specifies net radiative heat flow from attic ceiling to attic floor, not from the attic to the conditioned space. Net radiative heat flow from attic ceiling to attic floor warms the attic floor, but the attic floor in turns dissipates heats to the attic air and the attic walls [37].

The following eight figures show the radiative and conductive heat flows from the ceiling to the room below on four representative days of the year (the first days of January, April, July, and October) for a house in Fresno, California. The blue lines are for the base case regular roof, and the red lines for the comparison cool roof. The difference between the blue and red lines indicates the change in heat flux when changing from a regular roof to a cool roof.

Radiative Heat Flows Attic to Room Jan 1 -2

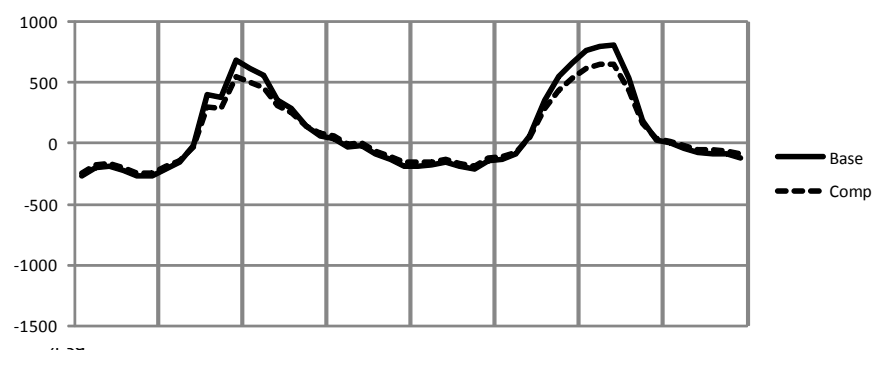

Conductive Heat Flows Attic to Room Jan 1 -2

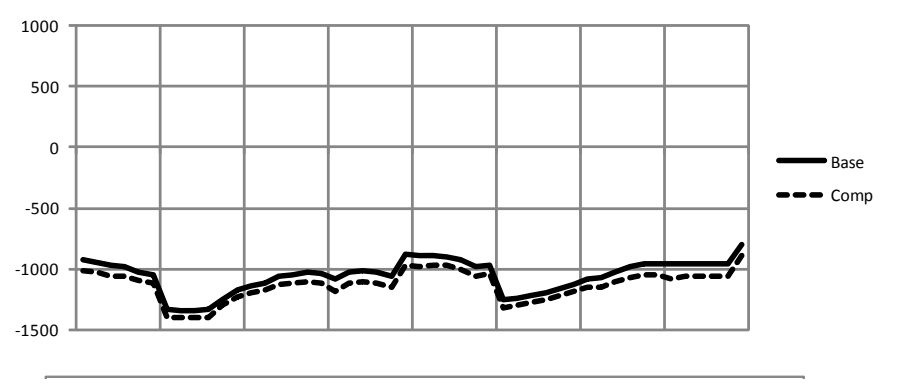

Figure 15. Ceiling heat flows with a regular roof and a Cool Roof in January 
Radiative Heat Flows Attic to Room Apr 1 -2

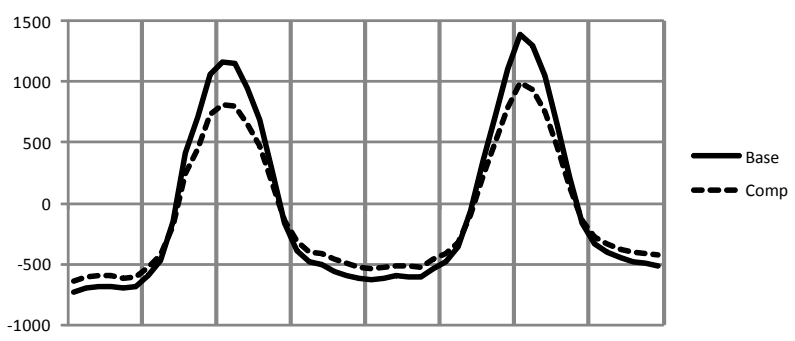

Conductive Heat Flows Attic to Room Apr 1 -2

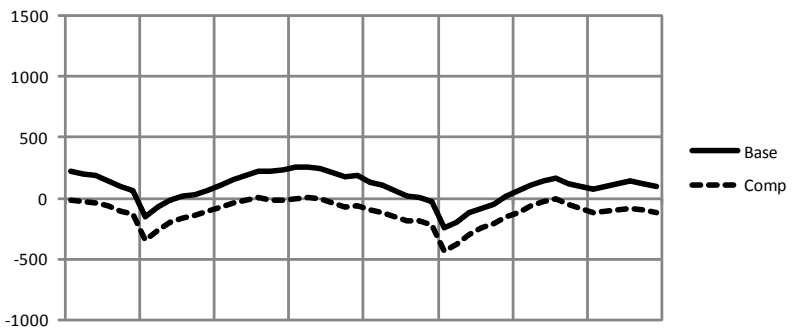

Figure 16. Ceiling heat flows with a regular roof and a Cool Roof in April

Radiative Heat Flows Attic to Space Jul 1 -2

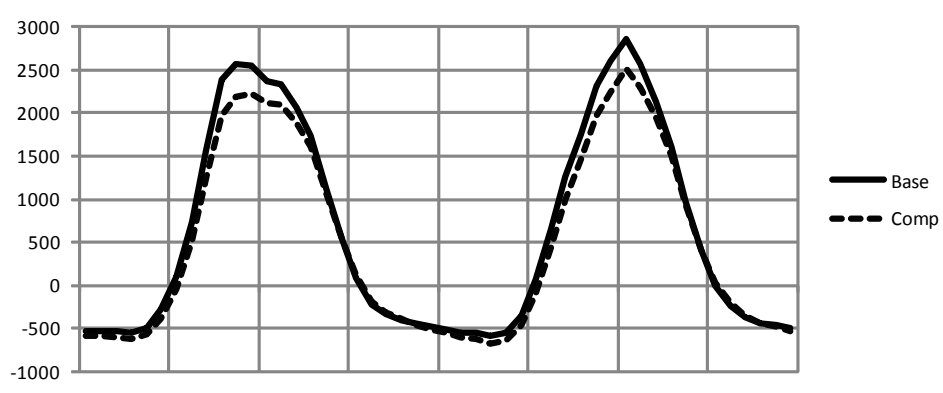

Conductive Heat Flows Attic to Space Jul 1 -2

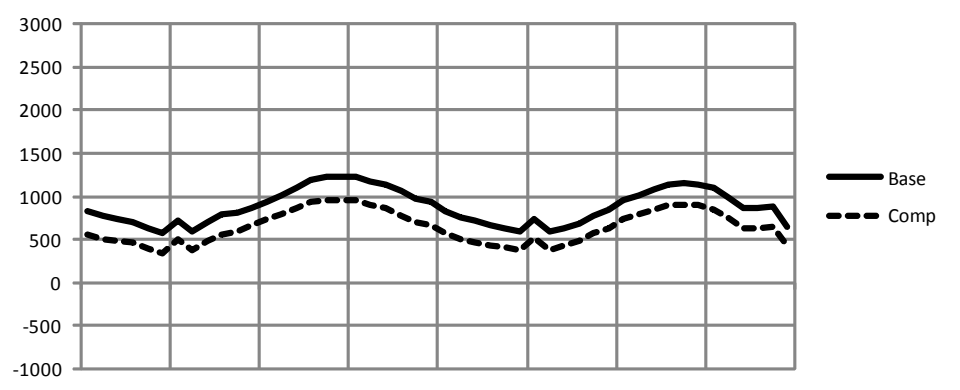

Figure 17. Ceiling heat flows with a regular roof and a Cool Roof in July 
Radiative Heat Flows Attic to Room Oct 1 -2

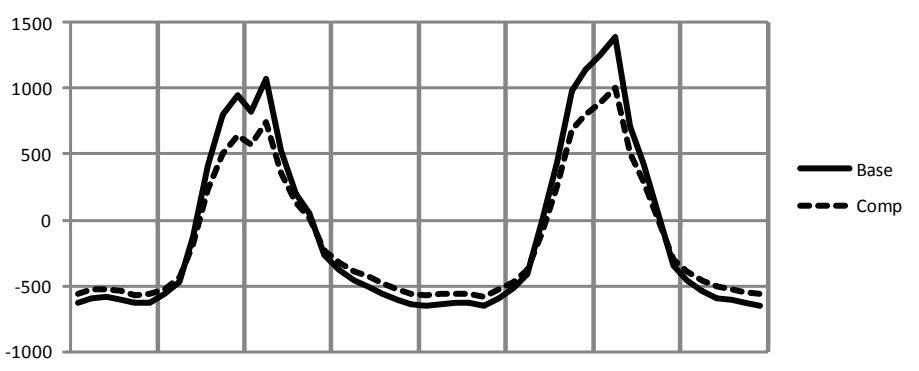

Conductive Heat Flows Attic to Room Oct 1 -2

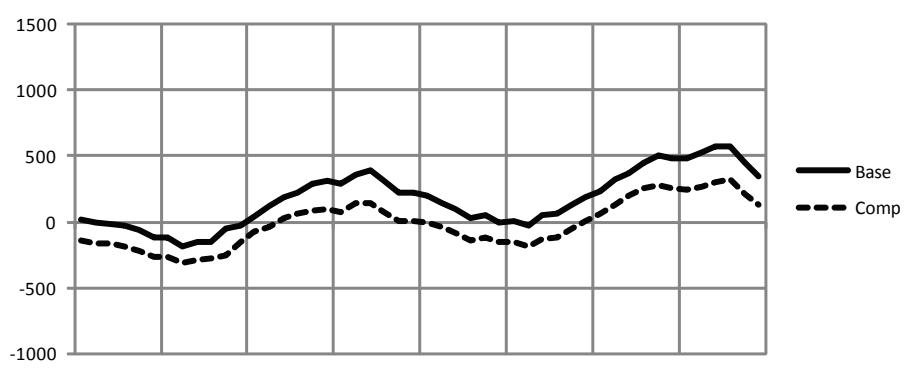

Figure 18. Ceiling heat flows with a regular roof and a Cool Roof in October

The plots reveal several interesting aspects:

1. The radiative component is positive during the day, but negative at night due to radiation to the sky.

2. The radiative component has a much more pronounced diurnal pattern and can be much larger than the conductive component, especially in the spring and fall when the differences between attic and room air temperatures are small.

3. The differences in conductive heat flows between the two roof options are often minimal in the winter, but significant in the other three seasons.

4. All of this indicates that a weighting-factor program such as $D O E-2.1 E$ is probably not the best tool to assess Cool Roof strategies that mainly change radiative heat flows through the ceiling.

A more detailed presentation of this preliminary analysis was given at a recent ASHRAE Conference held in Dallas late January 2013[27]. Overall, the conclusions were:

1. The radiative component of ceiling heat flows is significant and can often be greater than the conductive component, especially on warm winter days.

2. The main reason for the different heat flows between $D O E-2.1 E$ and doe2attic is that the former program either ignores or models more simplistically this radiative component.

In summary, the following observations were made:

- The ceiling heat flows deriving from the radiative heat transfer component between the underside of the roof and the attic's floor, walls, and HVAC ducts is very significant and can often be greater than the conduction component.

- The tentative reason why the results from $D O E-2$ (and other programs that treat ceiling heat flows as purely conduction) differ from AtticSim and EnergyPlus is that it is missing or models more simplistically this radiative component. 
- $\quad$ No methodological problem has been uncovered to date on the doe2attic engine, i.e., DOE-2.1E coupled with AtticSim, used in the RSC, outside of input issues with the duct model. However, further validation is ongoing and may uncover modeling issues as modeled and empirical data are compared.

\section{CONCLUSION AND FUTURE WORK}

In conclusion, the RSC [1] provides an approachable portal for both industry experts and residential homeowners to leverage the best available whole-building energy simulation packages and determine energy and cost savings for modern roof technologies and related retrofits. The tool uses the DOE-2.1E whole-building energy simulation program and calls AtticSim from the SYSTEMS module where AtticSim computes the temperatures and heat flows of all surfaces in the attic and passes back to DOE$2.1 E$ the attic air temperature, the HVAC duct gains and losses, and the ceiling heat flow. Combined, the two codes, benchmarked against field data including California demonstration homes at Ft. Irwin, were shown to yield credible results and are now usable online at www.roofcalc.com.

The preliminary analysis arrived at a tentative explanation for why the $R S C$ results differed from the previous LBNL studies and provides guidance for future analysis in the Task 1 comparison of three simulation programs (doe2attic, DOE-2.1E, EnergyPlus, and MicroPas) including heat exchange between the attic surfaces (principally the roof and ceiling), and the resultant heat flows through the ceiling to the building below. WBT will lead in analyzing the results from doe2attic and a standalone version of AtticSim, but will rely on Som Shrestha of ORNL for the EnergyPlus modeling and likely another consultant for the MicroPas modeling. To minimize the effort in calibrating the basic house models for the four programs, WBT is now exploring the possibility of fixing the air temperatures of the house below, which would allow the cross-program comparisons of only the heat flows through the ceiling.

\section{REFERENCES}

[1] Miller, W.A, J.R. New, J. Huang, E. Erdem, et al., “Roof Savings Calculator”. www.roofcalc.com

[2] Department of Energy, “DOE Cool Roof Calculator”. Oak Ridge National Laboratory, http://www.ornl.gov/sci/roofs+walls/facts/CoolCalcEnergy.htm

[3] Environmental Protection Agency, "Roofing Comparison Calculator" (no longer available). http://www.roofcalc.com/RoofCalcBuildingInput.aspx.

[4] Los Alamos Scientific Laboratory (1980). DOE-2 Reference Manual, Parts 1 and 2, Version 2.1. LA-7689-M Ver. 2.1, LBL-8706 Rev. 1, Lawrence Berkeley Laboratory, Berkeley CA and Los Alamos Scientific Laboratory, Los Alamos NM.

[5] Lawrence Berkeley Laboratory (1982). DOE-2 Engineers Manual, Version 2.1A. Lawrence Berkeley Laboratory, Berkeley CA.

[6] Winkelmann, F., Birdsall, B., Buhl, F., Ellington, K., Erdem, E., Hirsch, J., and Gates, S. (1993). DOE-2 Supplement, Version 2.1E. LBL-34947, Lawrence Berkeley National Laboratory, Berkeley CA.

[7] Huang, Y.J., Mitchell, R., Arasteh, A., and Selkowitz, S. 1999. "Residential fenestration performance analysis using RESFEN 3.1”. Thermal Performance of the Exterior Envelopes of Building VII conference, Clearwater Beach FL, also LBNL-42871. 
[8] American Society for Testing and Materials (ASTM), 2004. "Standard Practice for Estimation of Heat Gain or Loss through Ceilings under Attics Containing Radiant Barriers by Use of a Computer Program”. Standard C 1340-04. West Conshohocken, Penn.: American Society for Testing and Materials.

[9] Petrie, T. W., T. K. Stovall, and A. O. Desjarlais. 2004. "Comparison of Cathedralized Attics to Conventional Attics: Where and When Do Cathedralized Attics Save Energy and Operating Costs?” Thermal Performance of the Exterior Envelopes of Buildings IX, Atlanta: American Society of Heating, Refrigerating and Air-Conditioning Engineers.

[10] Parker, D., P. Fairey, and L. Gu. 1993. "Simulation of the Effects of Duct Leakage and Heat Transfer on Residential Space Cooling Energy Use”. Energy and Buildings, 20(2): 97-113.

[11] Petrie, T. W., K. E. Wilkes, P. W. Childs, and J. E. Christian. 1998. "Effect of Radiant Barriers and Attic Ventilation on Residential Attics and Attic Duct Systems: New Tools for Measuring and Modeling”. ASHRAE Trans., vol. 104, 1175-1192.

[12] Ober, D.G. and Wilkes, K.E. 1997. “An Energy Calculation Method for Attics, Including Radiant Barriers”. ASHRAE Research project RP717 for TC4.7, Feb. 1997.

[13] Miller, W. A. 2006. “The Effects of Infrared-Blocking Pigments and Deck Venting on StoneCoated Metal Residential Roofs”. ORNL/TM-2006/9. Oak Ridge, Tenn.: Oak Ridge National Laboratory.

[14] Miller, W. A., M. Keyhani, T. Stovall and A. Youngquist. 2007. "Natural Convection Heat Transfer in Roofs with Above-Sheathing Ventilation”. Thermal Performance of the Exterior Envelopes of Buildings $X$. Atlanta: American Society of Heating, Refrigerating and Air-Conditioning Engineers.

[15] Stephenson, D. G. and Mitalas, G.P. (1981) “Calculation of Heat Conduction Transfer Functions for Multi-Layer Slabs”. ASHRAE Transactions 77, Part II, 117.

[16] Huang, Y.J., Akbari, H., Rainer, L., and Ritschard, R.L. 1990. "481 prototypical commercial buildings for twenty urban market areas (Technical documentation of building loads data base developed for the GRI Cogeneration Market Assessment Model)". LBL Report 29798.

[17] Torcellini, P., Deru, M., Griffith, G., Benne, K., Halverson, M., Winiarski, D., and Crawley, D. 2008. "DOE Commercial Building Benchmark Models“. 2008 ACEEE Summer Study on Energy Efficiency in Buildings, Pacific Grove CA.

[18] World Wide Web Consortium (W3C), “HTML 4.01 Specification”. http://www.w3.org/TR/html4

[19] World Wide Web Consortium (W3C), “Cascading Style Sheets”. http://www.w3.org/Style/CSS

[20] Lerdor, Rasmus, “PHP: Hypertext Processor”. http://php.net/index.php

[21] Resig, John, “jQuery project”. http://jqueryui.com/themeroller

[22] F. W. Dodge. 2002. “Construction Outlook Forecast”. www.fwdodge.com. F.W. Dodge Market Analysis Group, Lexington, Mass.

[23] Akbari, H. and S. Konopacki 2005a. "Calculating energy-saving potentials of heat-island reduction strategies", Energy Policy 33, pp. 721-756, Elsevier.

[24] Akbari, H. and S. Konopacki 2005b. Unpublished data tables from DOE-2.1E simulations of Cool Roofs in medium-sized offices in 14 U.S. climates.

[25] Akbari, H., C. Wray, T. Xu, and R. Levinson 2006. "Inclusion of Solar Reflectance and Thermal Emittance Prescriptive Requirements for Residential Roofs in Title 24", Code Change Proposal for 2008 Title 24 Building Energy Efficiency Standards Update, California Energy Commission, Sacramento, CA.

[26] Koschenz, M. 2000. "Calculation of inside surface temperatures in DOE-2", pp. 2.132-2.135 in 
"DOE-2.1E, Version 107 Documentation Update Package", Simulation Research Group, Lawrence Berkeley National Laboratory, Berkeley CA.

[27] Huang, Y.J. 2013. "Uncertainty and Shortcomings in Using Building Energy Simulations to Estimate Energy Savings from Cool Roofs". Presentation given in Seminar 56, ASHRAE Conference, Jan. 26-30, Dallas TX.

[28] Petrie, T. W., Atchley, J. A., Childs P. W., and Desjarlais, A. O. "Effect of Solar Radiation Control on Energy Costs - A Radiation Control Fact Sheet for Low-Slope Roofs,” Proceedings of Performance of the Exterior Envelopes of Whole Buildings VIII, December, 2001.

[29] Petrie, T. W., Wilkes, K. E., and Desjarlais, A. O., "Effect of Solar Radiation Control on Electricity Demand Costs-An Addition to the DOE Cool Roof Calculator" Performance of Exterior Envelopes of Whole Buildings IX International Conference, ASHRAE, December, 2004. Available WWW: http://www.ornl.gov/sci/roofs+walls/staff/papers/new_64.pdf, July 26, 2013.

[30] National Renewable Energy Laboratory, "Dynamic Maps, GIS data, and Analysis Tools", 2005. Available WWW: http://www.nrel.gov/gis/solar.html

[31] American Society of Heating, Refrigerating and Air-Conditioning Engineers, Inc. (2007). Ashrae standard 90.1. Atlanta, GA. Available WWW: https://law.resource.org/pub/us/code/ibr/ashrae.90.1.ip.2010.pdf

[32] Lawrence Berkeley National Laboratory, "The Cool Colors Project," 2005. Available WWW: http://coolcolors.Ibl.gov/assets/docs/SRI\%20Calculator/SRI-calc10.xls

[33] Cool Roof Rating Council, 2013. Available WWW: http://www.coolroofs.org/codes and programs.html\#rebate

[34] Iu, Ipseng and Fisher, D.E. "Application of Conduction Transfer Functions and Periodic Response Factors in Cooling Load Calculation Procedures" ASHRAE Transactions 2004, vol. 109, part 2, pp. 829-841. Available WWW: http://www.hvac.okstate.edu/research/documents/iu fisher 04.pdf

[35] U.S. Dept. of Energy. "Building Energy Data Book." D\&R International, Ltd., 2010. Available WWW: http://buildingsdatabook.eren.doe.gov/docs\%5CDataBooks\%5C2008 BEDB Updated.pdf

[36] Levinson, Ronnen M. and Akbari, Hashem. "Potential benefits of cool roofs on commercial buildings: conserving energy, saving money, and reducing emission of greenhouse gases and air pollutants." Energy Efficiency Journal, 2010, vol. 3, pp. 53-109. Available WWW: http://heatisland.lbl.gov/publications/potential-benefits-cool-roofscommercial-buildings-conserving-energy-saving-money-and-r

[37] Hall, J.A. 1986. "Performance Testing of Radiant Barriers." In Proceedings of the Third Symposium on Improving Building Systems in Hot and Humid Climates. Report EESL-HH86-11-10. Arlington, TX, pages 57-68. Available WWW: http://repository.tamu.edu/handle/1969.1/6869

[38] Konopacki S, Akbari H, Pomerantz M, Gabersek S, Gartland L. 1997. Cooling energy savings potential of light-colored roofs for residential and commercial buildings in $11 \mathrm{US}$ metropolitan areas. LBNL-39433, Page 113. Lawrence Berkeley National Laboratory, Berkeley CA. Available WWW: http://dx.doi.org/10.2172/508151

[39] Gao Y, Xu J, Yang S, Tang X, Zhou Q, Ge J, Levinson R. 2013. Potential benefits of cool roofs in China: energy, cost and emission savings. Submitted to Building Research and Information. 


\section{APPENDIX A: NOMENCLATURE}

\begin{tabular}{|l|l|}
\hline AJAX & Asynchronous JavaScript and XML \\
\hline API & application programming interface \\
\hline CSS & Cascading Style Sheets \\
\hline DHTML & Dynamic HyperText Markup Language \\
\hline DOE & Department of Energy \\
\hline DOM & Document Object Model \\
\hline EPA & Environmental Protection Agency \\
\hline HVAC & Heating Ventilation and Air Conditioning \\
\hline JSON & JavaScript Object Notation \\
\hline PHP & Personal Home Page \\
\hline PVC & PolyVinylChloride thermoplastic membranes \\
\hline PIER & Public Interest Energy Research \\
\hline RSC & Roof Savings Calculator \\
\hline SR & Thelar reflectance \\
\hline TE & thermal emittance \\
\hline R & Thermal resistance (hr ft ${ }^{2} \mathrm{~F} /$ Btu) \\
\hline SI & \\
\hline
\end{tabular}




\section{APPENDIX B: CAPABILITIES SUPPORTED BY RSC}

The Project Advisory Committee defined a set of questions and answers that RSC was to support. In addition, the calculator was to support all relevant capabilities from other calculators while minimizing the number of questions a user must answer. The summary of comparative analysis between these calculators, documents, and the current version of the calculator are listed below.

\begin{tabular}{|l|c|c|c|c|c|}
\hline & RSC & $\begin{array}{c}\text { PAC } \\
\text { Slides }\end{array}$ & $\begin{array}{c}\text { PAC } \\
\text { QRpt }\end{array}$ & DOE $^{[2]}$ & EPA $^{[2]}$ \\
\hline Building Type & $\checkmark$ & $\checkmark$ & $\checkmark$ & & $\checkmark$ \\
\hline Location & $\checkmark$ & $\checkmark$ & & $\checkmark$ & $\checkmark$ \\
\hline Days of Operation per week & & $\checkmark$ & $\checkmark$ & & $\checkmark$ \\
\hline Building stock & $\checkmark$ & $\checkmark$ & & & $\checkmark$ \\
\hline Cooling system efficiency (SEER) & $\checkmark$ & $\checkmark$ & $\checkmark$ & $\checkmark$ & $\checkmark$ \\
\hline Type of heating & $\checkmark$ & $\checkmark$ & $\checkmark$ & $\checkmark$ & $\checkmark$ \\
\hline Heating system efficiency & $\checkmark$ & $\checkmark$ & $\checkmark$ & $\checkmark$ & $\checkmark$ \\
\hline Duct location & $\checkmark$ & $\checkmark$ & $\checkmark$ & & \\
\hline Level of roof/ceiling insulation & $\checkmark$ & $\checkmark$ & $\checkmark$ & $\checkmark$ & $\checkmark$ \\
\hline Above-sheathing ventilation & $\checkmark$ & $\checkmark$ & & & \\
\hline Radiant barrier & $\checkmark$ & $\checkmark$ & & & \\
\hline Roof thermal mass & $\checkmark$ & $\checkmark$ & & & \\
\hline Roof solar reflectance & $\checkmark$ & $\checkmark$ & $\checkmark$ & $\checkmark$ & $\checkmark$ \\
\hline Roof solar reflectance (black compare) & $\checkmark$ & & $\checkmark$ & & $\checkmark$ \\
\hline Roof thermal emittance & $\checkmark$ & $\checkmark$ & $\checkmark$ & $\checkmark$ & \\
\hline Roof thermal emittance (black compare) & $\checkmark$ & & $\checkmark$ & & \\
\hline Internal load & & $\checkmark$ & & & \\
\hline Conditioned space under roof & & $\checkmark$ & & & \\
\hline Gas and electricity costs & $\checkmark$ & $\checkmark$ & $\checkmark$ & $\checkmark$ & $\checkmark$ \\
\hline Inclination / Roof Area & $\checkmark$ & & & & $\checkmark$ \\
\hline HVAC Schedule & & & $\checkmark$ & & \\
\hline Conditioned space (ft ${ }^{2}$ ) & $\checkmark$ & & & & $\checkmark$ \\
\hline Number of floors & $\checkmark$ & & & & \\
\hline Window-to-wall ratio & $\checkmark$ & & & & \\
\hline
\end{tabular}




\section{APPENDIX C: COOLING SITE ENERGY SAVINGS AND HEATING SITE ENERGY}

PENALTY COMPARISON
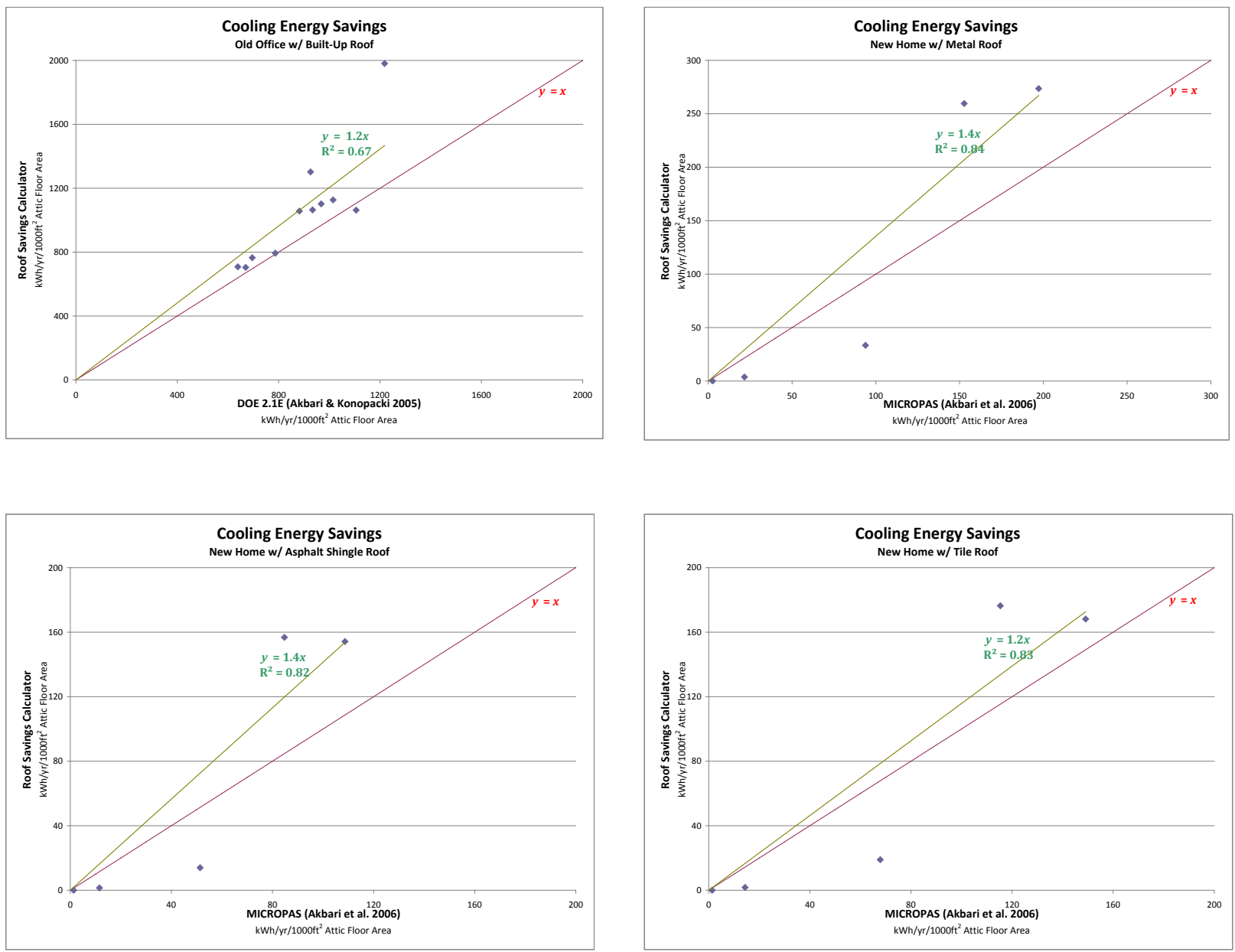

Cooling site energy savings 

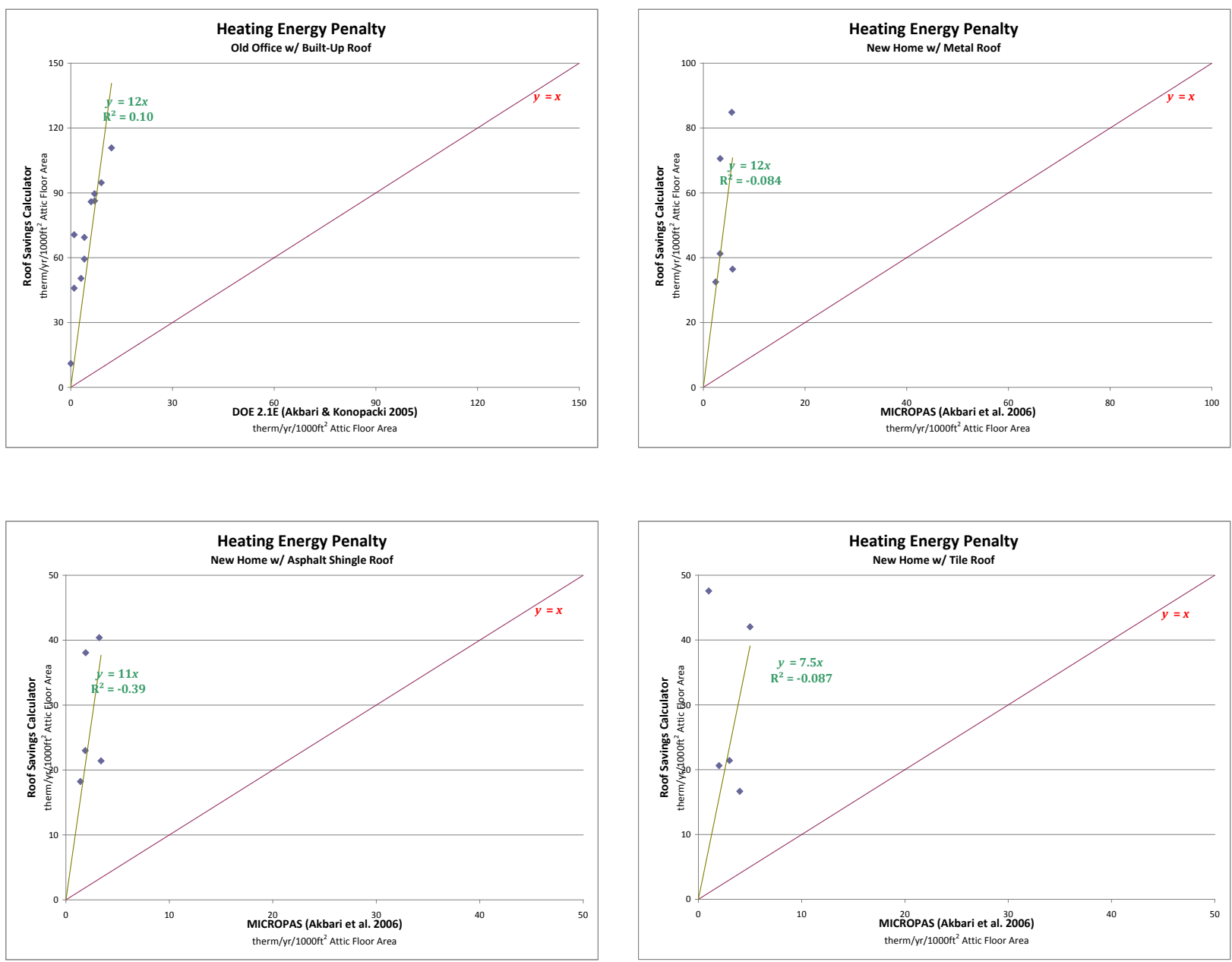

Heating site energy penalty 


\section{APPENDIX D: BASE CASE ELECTRICITY AND GAS USE COMPARISON}
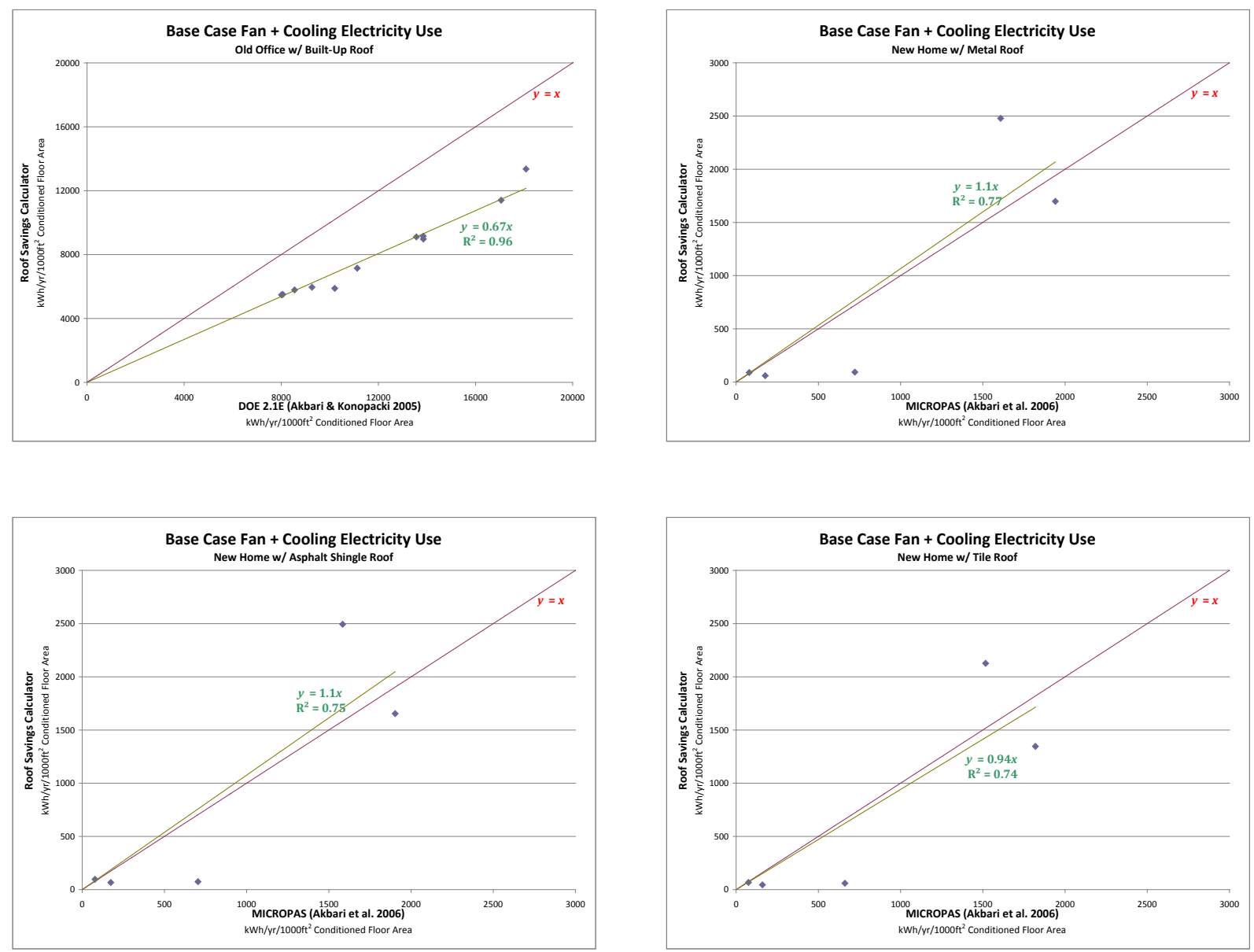

Base case fan + cooling site electricity use 

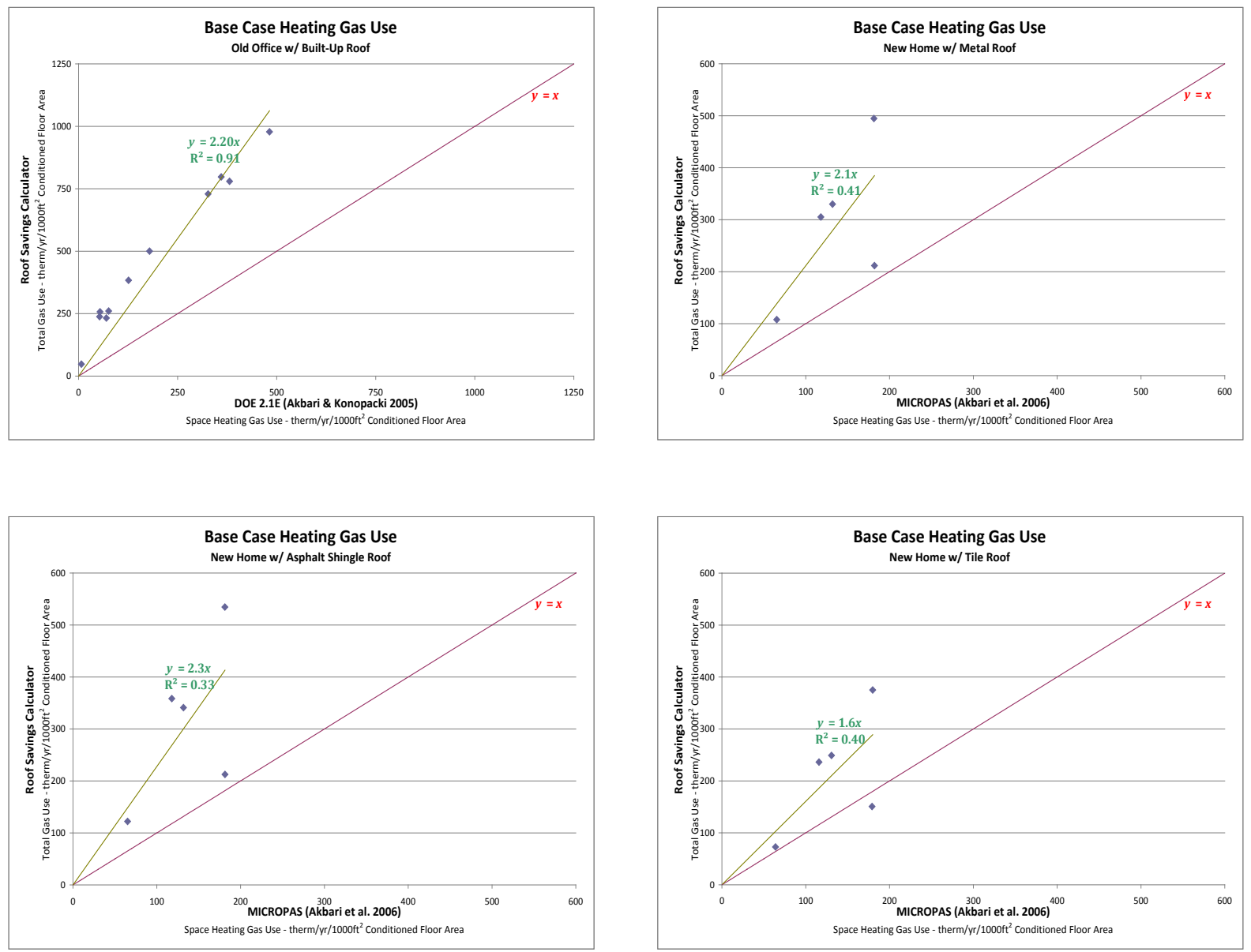

Base case heating site gas use: total (RSC) vs. space only (prior studies) 
(no chart for old office)
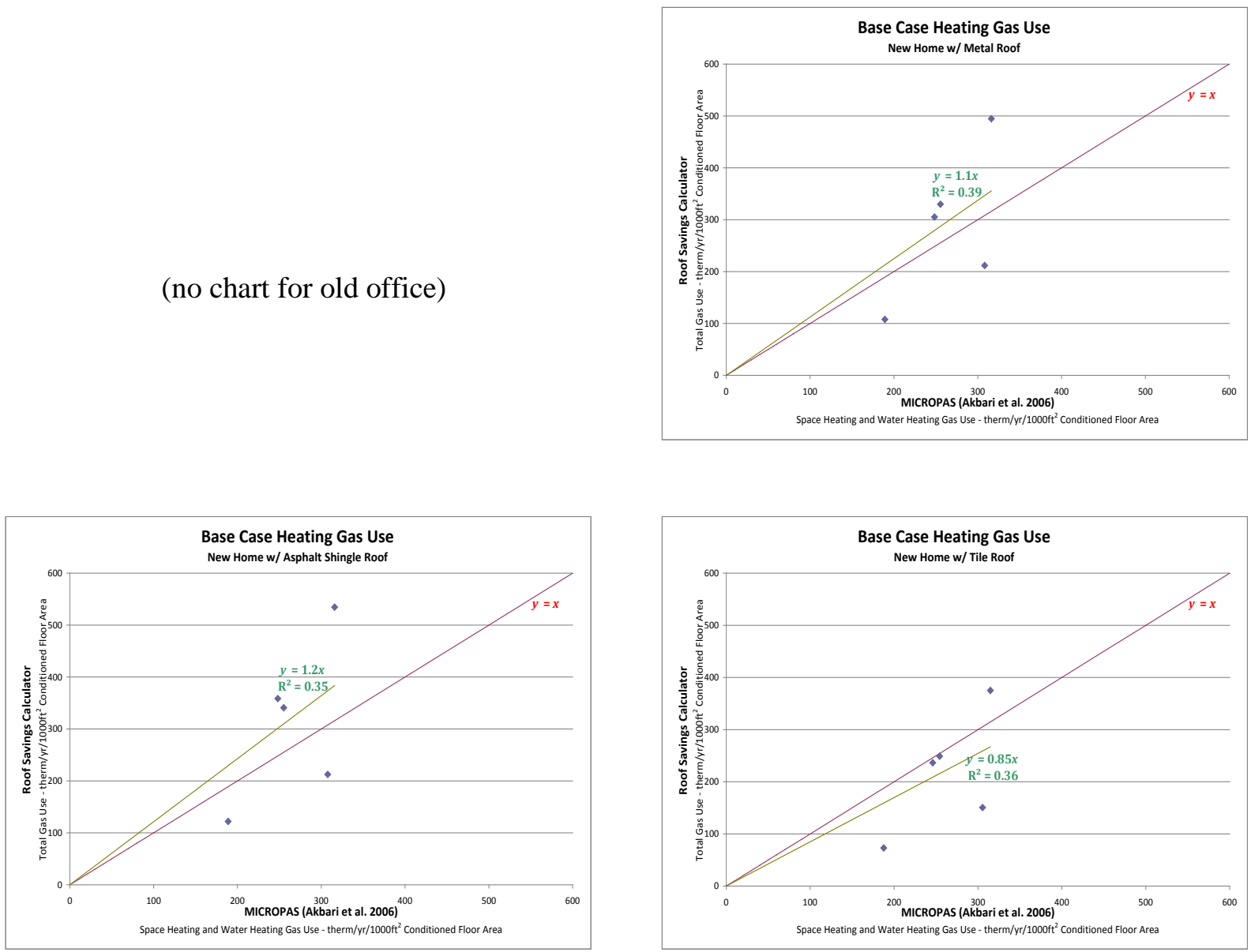

Base case heating site gas use: total (RSC) vs. space + water (prior studies) 


\section{APPENDIX E: NET SOURCE ENERGY SAVINGS}
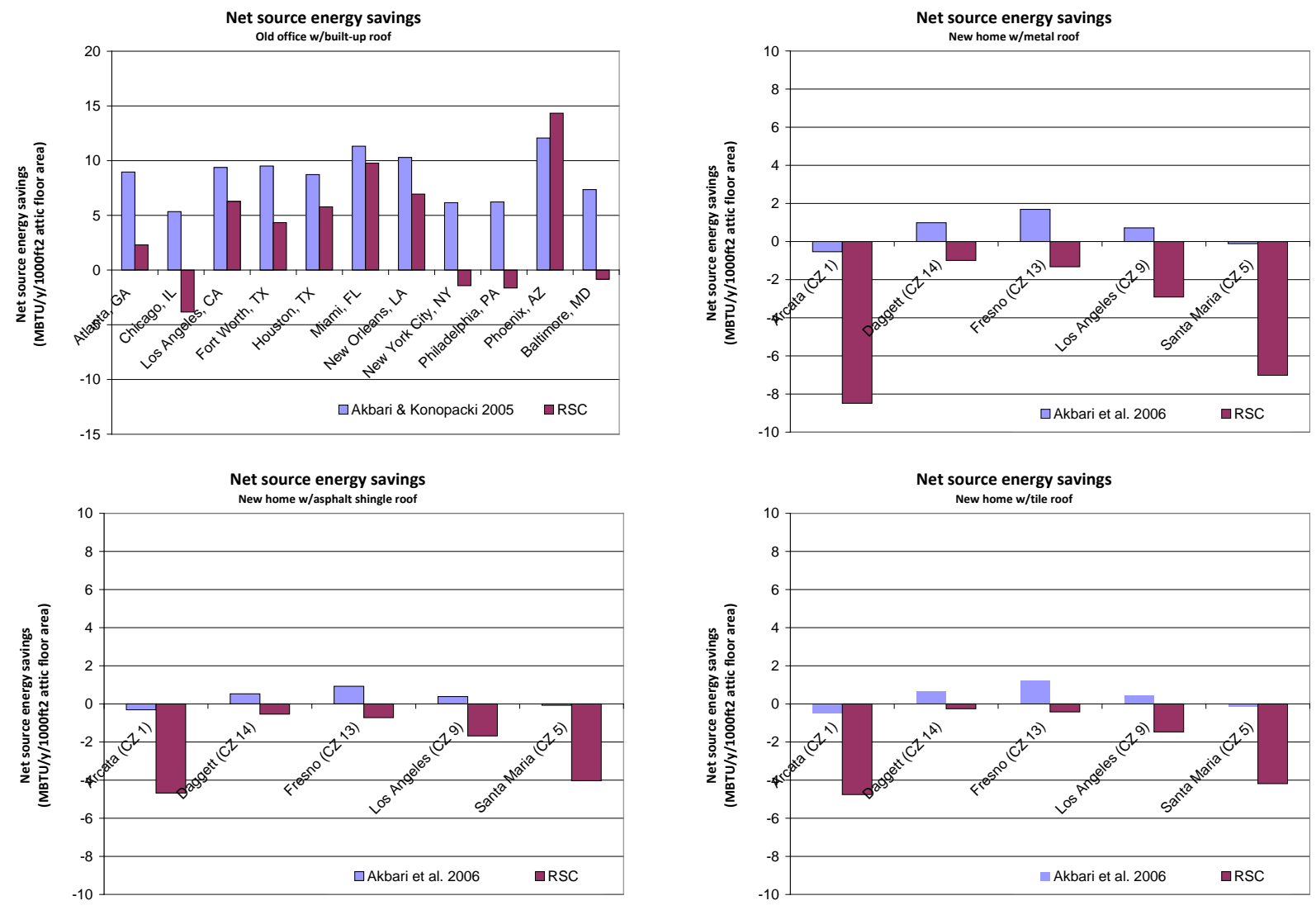

Net source energy savings (cooling source energy savings - heating source energy penalty) 


\section{APPENDIX F: DETAILS OF OLD OFFICE AND NEW HOME SIMULATIONS}

\begin{tabular}{|c|c|c|}
\hline & Akbari \& Konopacki 2005 & RSC \\
\hline Simulation tool & DOE2.1E & DOE2.1E \\
\hline Prototype & $\begin{array}{l}\text { Old office: } 4900 \text { sq ft conditioned floor area, } \\
4900 \text { sq ft attic floor area, } 1 \text { floor, pre-1980, } \\
\text { low slope BUR, no radiant barrier, gas } \\
\text { furnace, R- } 7 \text { ceiling, R- } 6 \text { walls, } 2.3 \text { COP, } 8 \\
\text { EER, } 70 \% \text { heating efficiency, } 20 \% \text { duct } \\
\text { leakage, roof TE } 0.90 \text {; base case roof SR } \\
0.20 \text {, cool case roof SR } 0.60\end{array}$ & $\begin{array}{l}\text { Old office: } 4900 \text { sq ft conditioned } \\
\text { floor area, } 4900 \text { sq ft attic floor } \\
\text { area, } 1 \text { floor, pre-1980, low slope } \\
\text { BUR, no radiant barrier, gas } \\
\text { furnace, no above-sheathing } \\
\text { ventilation, R-7 ceiling, } 70 \% \\
\text { heating efficiency, } 8.4 \text { SEER ( } \\
\text { equivalent to } 8 \text { EER), } \\
\text { uninspected ducts in attic; roof } \\
\text { TE } 0.90 \text {; base case roof SR } 0.20 \text {, } \\
\text { cool case roof SR } 0.60\end{array}$ \\
\hline Locations & $\begin{array}{l}\text { Atlanta, GA } \\
\text { Chicago, IL } \\
\text { Los Angeles, CA } \\
\text { Fort Worth, TX } \\
\text { Houston, TX } \\
\text { Miami, FL } \\
\text { New Orleans, LA } \\
\text { New York City, NY } \\
\text { Philadelphia, PA } \\
\text { Phoenix, AZ } \\
\text { Baltimore, MD }\end{array}$ & same \\
\hline $\begin{array}{l}\text { Cooling energy } \\
\text { savings metric }\end{array}$ & decrease in (fan + space cooling electricity) & $\begin{array}{l}\text { decrease in (space cooling } \\
\text { electricity) }\end{array}$ \\
\hline $\begin{array}{l}\text { Heating energy } \\
\text { penalty metric }\end{array}$ & increase in (space heating gas) & increase in (total gas) \\
\hline $\begin{array}{l}\text { Base case electricity } \\
\text { use }\end{array}$ & fan + space cooling electricity & same \\
\hline Base case gas use & space heating gas & total gas \\
\hline Notes & used raw data tables from Hashem & $\begin{array}{l}\text { obtained base case energy uses } \\
\text { from DOE-2 output files }\end{array}$ \\
\hline
\end{tabular}

\section{Details of old office simulations}




\begin{tabular}{|l|l|l|}
\hline & Akbari et al. 2006 & RSC \\
\hline Simulation tool & MICROPAS & DOE2.1E \\
\hline Prototype & $\begin{array}{l}\text { New home: 1761 sq ft conditioned floor } \\
\text { area, 1261 sq ft attic floor area, 5:12 roof } \\
\text { pitch, 78\% heating efficiency, 13 SEER, R- } \\
\text { 30 ceiling adjusted to "standard" } \\
\text { performance R-18.8 in CA CZ 2-10, R-38 } \\
\text { ceiling adjusted to "standard" performance } \\
\text { R-21.6 elsewhere, no radiant barrier, } \\
\text { inspected ducts in attic; TE 0.85; base case } \\
\text { roof SR 0.10; cool case roof SR 0.25 for } \\
\text { shingle, 0.35 for metal \& tile (was SR 0.40 } \\
\text { for metal \& shingle in report; savings \& } \\
\text { penalties scaled by 0.25/0.30) }\end{array}$ & $\begin{array}{l}\text { sadiant barrier, no above- } \\
\text { sheathing ventilation, R-18.8 } \\
\text { ceiling (CA CZ 2-10), R-21.6 } \\
\text { ceiling elsewhere, 78\% heating } \\
\text { efficiency, 13 SEER, inspected } \\
\text { ducts in attic; TE 0.85; base case } \\
\text { roof SR 0.10; cool case roof SR } \\
\text { 0.25 for shingle, 0.35 for metal \& } \\
\text { tile }\end{array}$ \\
\hline $\begin{array}{l}\text { Locations } \\
\text { Santa Maria, CA (CA CZ 5) } \\
\text { Los Angeles, CA (CA CZ 9) } \\
\text { Fresno, CA (CA CZ 13) } \\
\text { Daggett, CA (CA CZ 14) }\end{array}$ & same \\
\hline $\begin{array}{l}\text { Cooling energy } \\
\text { savings metric }\end{array}$ & $\begin{array}{l}\text { decrease in (space cooling compressor } \\
\text { electricity + space cooling fan electricity) }\end{array}$ & $\begin{array}{l}\text { decrease in (space cooling } \\
\text { electricity) }\end{array}$ \\
\hline $\begin{array}{l}\text { Heating energy } \\
\text { penalty metric }\end{array}$ & $\begin{array}{l}\text { increase in (space heating gas + 3*space } \\
\text { heating fan electricity) [note that expressed } \\
\text { in common units, the second term is only } \\
\text { about 4\% of the sum] }\end{array}$ & increase in (total gas) \\
\hline $\begin{array}{l}\text { Base case electricity } \\
\text { energy use }\end{array}$ & fan + space cooling electricity & same \\
\hline $\begin{array}{l}\text { Base case gas use } \\
\text { (comparison A) }\end{array}$ & space heating gas & total gas \\
\hline $\begin{array}{l}\text { Base case gas use } \\
\text { (comparison B) }\end{array}$ & space heating + water heating gas & total gas \\
\hline Notes & obtained raw data tables from Craig Wray & $\begin{array}{l}\text { obtained base case energy uses } \\
\text { from DOE-2 output files }\end{array}$ \\
\hline
\end{tabular}

Details of new home simulations 
APPENDIX G: OLD OFFICE AND NEW HOME CHART VALUES

\begin{tabular}{|c|c|c|c|c|c|}
\hline Old Office & DOE 2.1E & & & & \\
\hline Location & $\begin{array}{l}\text { cooling } \\
\text { electricity } \\
\text { savings } \\
\text { (kWh/y/100oft2 } \\
\text { attic floor area) }\end{array}$ & $\begin{array}{l}\text { space heating } \\
\text { gas penalty } \\
\text { (therm/y/1000ft2 } \\
\text { attic floor area) }\end{array}$ & $\begin{array}{l}\text { base case fan } \\
+ \text { cooling } \\
\text { electricity use } \\
\text { (kWh/y/1000ft2 } \\
\text { conditioned } \\
\text { floor area) }\end{array}$ & $\begin{array}{l}\text { base case gas } \\
\text { use } \\
\text { (therm/y/1000ft2 } \\
\text { conditioned } \\
\text { floor area) }\end{array}$ & $\begin{array}{l}\text { source energy } \\
\text { savings } \\
\text { (MBTU/y/1000ft2 } \\
\text { attic floor area) }\end{array}$ \\
\hline Atlanta, GA & 934 & 6.0 & 11128 & 179.0 & 9.0 \\
\hline Chicago, IL & 639 & 12.0 & 8010 & 482.0 & 5.3 \\
\hline $\begin{array}{l}\text { Los Angeles, } \\
\text { CA }\end{array}$ & 926 & 1.0 & 10201 & 54.0 & 9.4 \\
\hline $\begin{array}{l}\text { Fort Worth, } \\
\text { TX }\end{array}$ & 968 & 4.0 & 13565 & 126.0 & 9.5 \\
\hline Houston, TX & 882 & 3.0 & 13846 & 76.0 & 8.7 \\
\hline Miami, FL & 1106 & 0.0 & 17057 & 7.0 & 11.3 \\
\hline $\begin{array}{l}\text { New Orleans, } \\
\text { LA }\end{array}$ & 1015 & 1.0 & 13853 & 70.0 & 10.3 \\
\hline $\begin{array}{l}\text { New York } \\
\text { City, NY }\end{array}$ & 670 & 7.0 & 8062 & 381.0 & 6.2 \\
\hline $\begin{array}{l}\text { Philadelphia, } \\
\text { PA }\end{array}$ & 696 & 9.0 & 8546 & 360.0 & 6.2 \\
\hline Phoenix, AZ & 1218 & 4.0 & 18078 & 53.0 & 12.1 \\
\hline Baltimore, MD & 787 & 7.0 & 9263 & 327.0 & 7.4 \\
\hline
\end{tabular}

\begin{tabular}{|c|c|c|c|c|c|}
\hline Old Office & RSC & & & & \\
\hline Location & $\begin{array}{l}\text { cooling } \\
\text { electricity } \\
\text { savings } \\
\text { (kWh/y/1000ft2 } \\
\text { attic floor area) }\end{array}$ & $\begin{array}{l}\text { gas penalty } \\
\text { (therm/y/1000ft2 } \\
\text { attic floor area) }\end{array}$ & $\begin{array}{l}\text { base case fan } \\
\text { + cooling } \\
\text { electricity use } \\
\text { (kWh/y/1000ft2 } \\
\text { conditioned } \\
\text { floor area) }\end{array}$ & $\begin{array}{l}\text { base case total } \\
\text { gas use } \\
\text { (therm/y/1000ft2 } \\
\text { conditioned } \\
\text { floor area) }\end{array}$ & $\begin{array}{l}\text { source energy } \\
\text { savings } \\
\text { (MBTU/y/1000ft2 } \\
\text { attic floor area) }\end{array}$ \\
\hline Atlanta, GA & 1064.3 & 85.9 & 7152 & 500 & 2.3 \\
\hline Chicago, IL & 708.2 & 110.8 & 5479 & 978 & -3.8 \\
\hline $\begin{array}{l}\text { Los Angeles, } \\
\text { CA }\end{array}$ & 1302.3 & 70.6 & 5889 & 257 & 6.3 \\
\hline $\begin{array}{l}\text { Fort Worth, } \\
\text { TX }\end{array}$ & 1101.9 & 69.4 & 9107 & 383 & 4.3 \\
\hline Houston, TX & 1056.9 & 50.4 & 9149 & 260 & 5.8 \\
\hline Miami, FL & 1062.7 & 11.0 & 11403 & 48 & 9.8 \\
\hline $\begin{array}{l}\text { New Orleans, } \\
\text { LA }\end{array}$ & 1127.0 & 45.9 & 8978 & 232 & 6.9 \\
\hline $\begin{array}{l}\text { New York } \\
\text { City, NY }\end{array}$ & 704.3 & 86.3 & 5504 & 780 & -1.4 \\
\hline $\begin{array}{l}\text { Philadelphia, } \\
\text { PA }\end{array}$ & 765.1 & 94.7 & 5790 & 798 & -1.6 \\
\hline Phoenix, AZ & 1980.9 & 59.4 & 13358 & 238 & 14.3 \\
\hline
\end{tabular}




\begin{tabular}{|c|c|c|c|c|c|c|}
\hline Baltimore, MD & \multicolumn{2}{|c|}{793.3} & 89.6 & \multicolumn{2}{|l|}{5960} & 729 \\
\hline $\begin{array}{l}\text { New } \\
\text { Home }\end{array}$ & & MICROPAS & & & & \\
\hline Location & Material & $\begin{array}{l}\text { cooling } \\
\text { electricity } \\
\text { savings } \\
\text { (kWh/y/100 } \\
\text { Oft2 attic } \\
\text { floor area) }\end{array}$ & $\begin{array}{l}\text { space } \\
\text { heating gas } \\
\text { penalty } \\
\text { (therm/y/100 } \\
\text { Oft2 attic floor } \\
\text { area) }\end{array}$ & $\begin{array}{l}\text { base case } \\
\text { fan + cooling } \\
\text { electricity use } \\
\text { (kWh/y/1000f } \\
\text { t2 } \\
\text { conditioned } \\
\text { floor area) }\end{array}$ & $\begin{array}{l}\text { base case } \\
\text { space } \\
\text { heating } \\
\text { gas use } \\
\text { (therm/y/1 } \\
000 f t 2 \\
\text { conditione } \\
\text { d floor } \\
\text { area) }\end{array}$ & $\begin{array}{l}\text { base case } \\
\text { space } \\
\text { heating }+ \\
\text { water heating } \\
\text { gas use } \\
\text { (therm/y/100 } \\
\text { Oft2 } \\
\text { conditioned } \\
\text { floor area) }\end{array}$ \\
\hline Arcata (CZ 1) & metal & 3 & 5.6 & 79 & 181.4 & 316.2 \\
\hline Daggett (CZ 14) & metal & 153 & 5.7 & 1608 & 182 & 308.3 \\
\hline Fresno (CZ 13) & metal & 197 & 3.3 & 1941 & 132 & 255.5 \\
\hline $\begin{array}{l}\text { Los Angeles } \\
\text { (CZ 9) }\end{array}$ & metal & 94 & 2.4 & 722 & 65.4 & 189.2 \\
\hline $\begin{array}{l}\text { Santa Maria } \\
\text { (CZ 5) }\end{array}$ & metal & 22 & 3.3 & 177 & 118.1 & 248 \\
\hline Arcata (CZ 1) & shingle & 1 & 3.2 & 78 & 181.2 & 316 \\
\hline Daggett (CZ 14) & shingle & 85 & 3.4 & 1584 & 181.4 & 307.7 \\
\hline Fresno (CZ 13) & shingle & 109 & 1.9 & 1903 & 131.8 & 255.3 \\
\hline $\begin{array}{l}\text { Los Angeles } \\
\text { (CZ 9) }\end{array}$ & shingle & 51 & 1.4 & 704 & 65.2 & 189 \\
\hline $\begin{array}{l}\text { Santa Maria } \\
\text { (CZ 5) }\end{array}$ & shingle & 12 & 1.9 & 174 & 117.9 & 248.2 \\
\hline Arcata (CZ 1) & tile & 1 & 5.0 & 75 & 179.9 & 314.7 \\
\hline Daggett (CZ 14) & tile & 115 & 5.4 & 1517 & 179.2 & 305.5 \\
\hline Fresno (CZ 13) & tile & 149 & 2.9 & 1820 & 130.7 & 254.2 \\
\hline $\begin{array}{l}\text { Los Angeles } \\
\text { (CZ 9) }\end{array}$ & tile & 68 & 2.3 & 661 & 63.9 & 187.7 \\
\hline $\begin{array}{l}\text { Santa Maria } \\
\text { (CZ 5) }\end{array}$ & tile & 14 & 3.1 & 160 & 115.8 & 246.1 \\
\hline
\end{tabular}

\begin{tabular}{|c|c|c|c|c|c|c|c|}
\hline $\begin{array}{l}\text { New } \\
\text { Home }\end{array}$ & & RSC & & & & & \\
\hline Location & Material & $\begin{array}{l}\text { source } \\
\text { energy } \\
\text { savings } \\
\text { (MBTU/y/10 } \\
\text { 00ft2 attic } \\
\text { floor area) }\end{array}$ & $\begin{array}{l}\text { cooling } \\
\text { electricity } \\
\text { savings } \\
\text { (kWh/y/100 } \\
\text { Oft2 attic } \\
\text { floor area) }\end{array}$ & $\begin{array}{l}\text { gas } \\
\text { penalty } \\
\text { (therm/y/10 } \\
\text { 00ft2 attic } \\
\text { floor area) }\end{array}$ & $\begin{array}{l}\text { base case } \\
\text { fan + space } \\
\text { cooling } \\
\text { electricity use } \\
\text { (kWh/y/1000f } \\
\text { t2 } \\
\text { conditioned } \\
\text { floor area) }\end{array}$ & $\begin{array}{l}\text { base case } \\
\text { total gas } \\
\text { use } \\
\text { (therm/y/10 } \\
\text { 00ft2 } \\
\text { conditioned } \\
\text { floor area) }\end{array}$ & $\begin{array}{l}\text { source } \\
\text { energy } \\
\text { savings } \\
\text { (MBTU/yl } \\
1000 f t 2 \\
\text { attic floor } \\
\text { area) }\end{array}$ \\
\hline Arcata (CZ 1) & metal & -0.53 & 0.0 & 84.9 & 90 & 495 & -8.5 \\
\hline Daggett (CZ 14) & metal & 0.99 & 259.6 & 36.5 & 2478 & 212 & -1.0 \\
\hline Fresno (CZ 13) & metal & 1.69 & 273.6 & 41.2 & 1698 & 330 & -1.3 \\
\hline $\begin{array}{l}\text { Los Angeles } \\
\text { (CZ 9) }\end{array}$ & metal & 0.72 & 33.4 & 32.5 & 94 & 108 & -2.9 \\
\hline $\begin{array}{l}\text { Santa Maria } \\
\text { (CZ 5) }\end{array}$ & metal & -0.11 & 3.7 & 70.6 & 59 & 305 & -7.0 \\
\hline Arcata (CZ 1) & shingle & -0.31 & 0.0 & 40.4 & 98 & 534 & -4.7 \\
\hline Daggett (CZ 14) & shingle & 0.53 & 156.8 & 21.4 & 2494 & 213 & -0.5 \\
\hline Fresno (CZ 13) & shingle & 0.93 & 154.2 & 23.0 & 1653 & 341 & -0.7 \\
\hline $\begin{array}{l}\text { Los Angeles } \\
\text { (CZ 9) }\end{array}$ & shingle & 0.39 & 14.0 & 18.2 & 75 & 122 & -1.7 \\
\hline
\end{tabular}




\begin{tabular}{|ll|rrrrrr|}
\hline Santa Maria & shingle & -0.07 & 1.4 & 38.1 & 67 & 358 & -4.0 \\
(CZ 5) & & -0.48 & 0.0 & 47.6 & 67 & 375 & -4.8 \\
Arcata (CZ 1) & tile & 0.64 & 176.4 & 20.6 & 2126 & 151 & -0.3 \\
Daggett (CZ 14) & tile & 1.24 & 168.1 & 21.4 & 1347 & 249 & -0.4 \\
Fresno (CZ 13) & tile & 0.47 & 19.0 & 16.7 & 60 & 73 & -1.5 \\
$\begin{array}{l}\text { Los Angeles } \\
\text { (CZ 9) }\end{array}$ & tile & -0.16 & 1.7 & 42.0 & 45 & 236 & -4.2 \\
$\begin{array}{l}\text { Santa Maria } \\
\text { (CZ 5) }\end{array}$ & tile & & & & & & \\
\hline
\end{tabular}




\section{APPENDIX H: MODELING AN ATTACHED RESIDENTIAL BUILDING}

Inquiries by the Roof Coating Manufacturer's Association (RCMA) were made as to the complexity of adding an additional building type for attached (non-standalone) buildings, such as the brownstone residential buildings popular in New York City, since it is a significant portion of their market.

There is very little difference between the modeling of an attached and a detached residential building, except for the obvious differences in building geometry. BDL files exist for 16 prototypical multi-family (apartment) buildings, but are likely too detailed for the RSC since they model each apartment unit distinguished by their location in the building (top, middle, or ground floor; mid or end units). Rather than adding a new template file, changing the existing residential input template to support a house type of detached, townhouse, and apartment would be preferable. It is recommended that RSC limit the floor areas and number of floors, and calculate the perimeter lengths as follows:

A (area/floor) num of floors perimeter length detached $>600,<10,000<=3$ flrs A/28* 2 (same as before)

townhouse $>800$, no limit $>=2$ flrs $A / 28 * 2$

apartment $>2000$, no limit $>=2 \mathrm{flrs} A / 50 * 2$

The assumptions are that the townhouse is single-loaded, i.e., open to the outside on both ends, while the apartment has a double-loaded corridor (i.e., open to the outside on one side only). 


\section{APPENDIX I: DUCT MODELING QUESTION}

Questions regarding RSC's modeling of duct loss for $10 \%$ and 14\% were based on AtticSim's input sample file which included the following numbers:

ductIn CoolFlow CoolLeak HeatFlow HeatLeak

AT-DUCT-SUP-1 $36.42 \quad 4673.4 \quad 5.8207 \quad 3785.6 \quad 3.9122$

AT-DUCT-RET-1 $41.49 \quad 4494.2 \quad 4.3191 \quad 3644.4 \quad 3.4258$

AtticSim documentation states leakages are per "unit length". Is that per foot or per segment length? If per foot, total leakage fraction would be (Leak*Duct)/Flow but values of 0.04536 and 0.03764 for aTDUCT-SUP-1 and 0.039873 and 0.0390 for AT-DUCT-RET-1 are obtained.

It is correct that the leakage fractions in the template files are $4 \% ; 4 \%$ and $14 \%$ were used as the inspected and uninspected duct leakage rate defaults [1] in the public RSC, though there is an option to scale to other values if necessary.

[1] Cummings, J. B., Tooley, J. J., Moyer, N. A. and Dunsmore, R., "Impacts of Duct Leakage on Infiltration Rates, Space Conditioning Energy Use, and Peak Electrical Demand in Florida Homes," FSEC-PF-217-96. Proceedings of the ACEEE 1990 Summer Study, Pacific Grove, CA, August 1990. 


\section{APPENDIX J: PRELIMINARY ANALYSIS ON THE FORCE MULTIPLIER OF RSC HEATING PENALTIES AND THE ROLE OF RADIATIVE HEAT EXCHANGE IN AN ATTIC ASSEMBLY}

In determining the difference of the previous results and the simulation engines on which they are based, it is important to understand the algorithmic differences underlying their modeling capabilities. To investigate, a software system for testing was set up that allows running AtticSim, DOE-2, or RSC independently. There is a thermal history relevant to this analysis question since AtticSim is using DOE$2.1 \mathrm{E}$ to get the boundary conditions every hour. While there could be an error in the implementation of doe2attic's integrated source code, it is also possible that DOE-2 and AtticSim produce very different results. This is likely under temperate conditions like Fresno, where the attic temperatures are fluctuating around the zone temperature below, making the attic loads very dynamic. Ceiling heat transfer in DOE-2 is quick/instantaneous, while in AtticSim it is delayed (since it uses DOE-2 data from the previous hour as boundary conditions); this can significantly impact hourly results. Looking at the differences is important, but can also be considered looking at symptoms rather than causes due to the fact that they are so far downstream (hourly ceiling heat fluxes => hourly system loads => difference in hourly system loads $=>$ differences in total system loads).

It is debated extensively in ASHRAE Technical Committee 4.7 as to the extent, with all software and empirical studies, whether DOE-2 has been thoroughly validated since uncertainty in modeling inputs drives the results. Moreover, the DOE-2.1E attic model is a known deficiency such that there are few validation efforts. AtticSim has been accepted as an ASTM standard so the algorithms are judged to be satisfactory, but can still suffer from discrepancies from controlled studies and uncertainties in inputs.

As reported in this document, RSC reports significant differences for heating penalty compared to previous studies. To facilitate analysis, a modified version of RSC simulations was used to run DOE-2.1E with and without the AtticSim model in DOE-2 Systems. This observation is true with and without the duct model (Duct_loc=Space). As an example, results for Run 24495 (Fresno, residential) are as follows:

AtticSim not used (i.e., using the standard DOE-2.1E attic)

$\begin{array}{cll}\text { Base } & \text { Heating Fuel } & \text { 20.078 MBtu Cooling Elec } 1248 \mathrm{kWh} \\ \text { Comp } & \text { Heating Fuel } & \text { 20.353 MBtu Cooling Elec } 1211 \mathrm{kWh} \\ & \text { Penalty } & 0.275 \mathrm{MBtu} \\ \text { avings } & 37 \mathrm{kWh} & \end{array}$

AtticSim used (i.e., recalculating the attic temperatures using AtticSim)

Base $\quad$ Heating Fuel 36.037 MBtu Cooling Elec $2007 \mathrm{kWh}$

Comp Heating Fuel 38.398 MBtu Cooling Elec 1794 kWh

Penalty 2.361 MBtu

Savings $\quad 213 \mathrm{kWh}$

There are combinations of effects that are believed to coincidentally result in the "magnitude greater" heating penalties reported in this document. There are two separate and separable modeling issues that are relevant include: (1) the inputs for the duct system, and (2) how to hook up the one-zone AtticSim model when the space below has multiple zones (as is the case of the medium office with the 5zones - 4 perimeter and 1 core). 
In testing, RSC and previous simulations were compared. To isolate the role of the duct, the duct system was selected as being in conditioned space rather than the attic. For residential simulations, energy consumption fell by more than half (44.10 to $21.16 \mathrm{MBtu}$ ) in heating, but only a quarter (1948 to 1621 $\mathrm{kWh}$ ) in cooling for Run 24495 base case (Fresno). This indicates that the duct system, as modeled, has duct losses of $>50 \%$ during the heating season and $25 \%$ during the cooling season. Modera et al estimated $10-15 \%$ for heating and $25-40 \%$ for cooling. This is in agreement with Cummings et al. and Roberts et al. The correction applied to correct for these duct losses is discussed further in Appendix K: Extensions to the AtticSim duct model. Tests were conducted with the following configurations: as is, no duct system, and no duct system and no AtticSim (i.e., standard DOE-2.1E) with a 5-zone and 1-zone version of the medium office building. AtticSim produced somewhat higher heating loads, and heating penalties (base comp) about five times greater than did DOE-2.1E (1.44MBtu for 24495r, 0.27MBtu for 24495rnoAS), which the duct system would double again to the "order of magnitude" difference.

As for the second complicating factor, the current RSC uses a plenum that would receive heat gain/loss from the attic and translate that to the multiple zones below (if more than one as in the case of the medium office building). In the simulations without AtticSim, heating loads dropped to 1/3 but the cooling loads stayed fairly constant. By eliminating the plenum and lumping the 5 zones into one, building heating and cooling loads stayed fairly constant between all three cases. The heating penalty using DOE-2.1E alone is 3.60MBtu and using AtticSim is 6.60MBtu, while the old 5-zone model they were 3.0MBtu and 30.1 MBtu respectively.

Preliminary conclusions and recommendations are as follows:

1. AtticSim shows from 2-5 times more sensitivity in heating penalties in cool roofs than does DOE-2.1E. Possible reasons - AtticSim is a heat balance program that models the surface temperatures whereas DOE-2 is a weighting factor program that models the zone air temperature.

2. AtticSim provides the heat flow to the space below with the attic floor modeled as a delayed layer, whereas DOE-2 models it as a quick layer with no time delay

3. The current medium office (mdoffice) model has a plenum and 5 zones per floor which should be replaced by the 1 zone per floor model (mdoffice2). This will prevent erroneous tripling of the heating loads. The ultimate solution is to modify doe2attic to distribute the heat flow through the attic floor 4. Input values for the duct model in AtticSim need to be reviewed and more representative values chosen that would produce heating and cooling duct losses more in line with measured data. If there turns out be problems in the code itself (rather than the input values), the recommendation is that the RSC be used with the ducts always modeled more quickly as being in the space.

Note: the duct modeling simulation runtime has been diminished through modeling efforts described in Appendix K: Extensions to the AtticSim duct model.

\section{REFERENCES}

Cummings, J. B., Tooley, J. J., Moyer, N. A. and Dunsmore, R., "Impacts of Duct Leakage on Infiltration Rates, Space Conditioning Energy Use, and Peak Electrical Demand in Florida Homes," Proceedings of the ACEEE 1990 Summer Study, Pacific Grove, CA, August 1990. 
Modera, M., D. Dickerhoff, O. Nilssen, H. Duquette, J. Geyselaers. 1996. "Residential Field Testing of an Aerosol-Based Technology for Sealing Ductwork.” In Proceedings of the 1996 ACEEE Summer Study on Energy Efficiency in Buildings, Washington, DC: American Council for an Energy-Efficient Economy.

Roberts, David and Winkler, Jon, 2010. “Ducts in the Attic? What Were They Thinking?” Conference Paper NREL/CP-550-48163. In ACEEE Summer Study, Pacific Grove, CA, August 15-20, 2010. Available WWW: http://www.nrel.gov/docs/fy10osti/48163.pdf 


\section{APPENDIX K: EXTENSIONS TO THE ATTICSIM DUCT MODEL}

Several modifications have been made to the AtticSim code which are partially but not completely captured in the Subversion source control repository. The starting point for these modifications was the Fortran 90 version of the code created by Kaushik Biswas.

\section{CORRECTION TO HVAC LOADS DUE TO DUCTS}

A parametric study was performed with AtticSim in an effort to determine the impact of leaky supply and return ducts on the HVAC load. In this study three leaky-duct scenarios were examined: (1) leaks in supply ducts only, (2) leaks in return ducts only and (3) leaks in both supply and return ducts. The results indicated that when both supply and return ducts leaked the HVAC load was smaller than if there were leaks only in supply ducts or only in return ducts. Since this is physically incorrect, a closer examination of the code was undertaken. At each time step, AtticSim marches along the length of each duct doing detailed energy balances to determine the temperature of the air exiting the duct. The instantaneous load due to the ducts is then calculated as

$$
\dot{Q}_{\text {ducts }}=\sum_{i=1}^{N_{\text {ducts }}}\left(\dot{m}_{\text {in }} c_{p} T_{\text {in }}-\dot{m}_{\text {out }} c_{p} T_{\text {out }}\right)_{i}
$$

If there is no leakage from the ducts, Equation 1 is the load placed on the HVAC system due to the ducts. A positive value indicates energy loss from the ducts or a heating load. However, if there is leakage from a duct, this equation does not give the load due to the ducts. To illustrate this, consider a simple case with a leaky supply duct and a non-leaky return duct as shown in Figure 19.

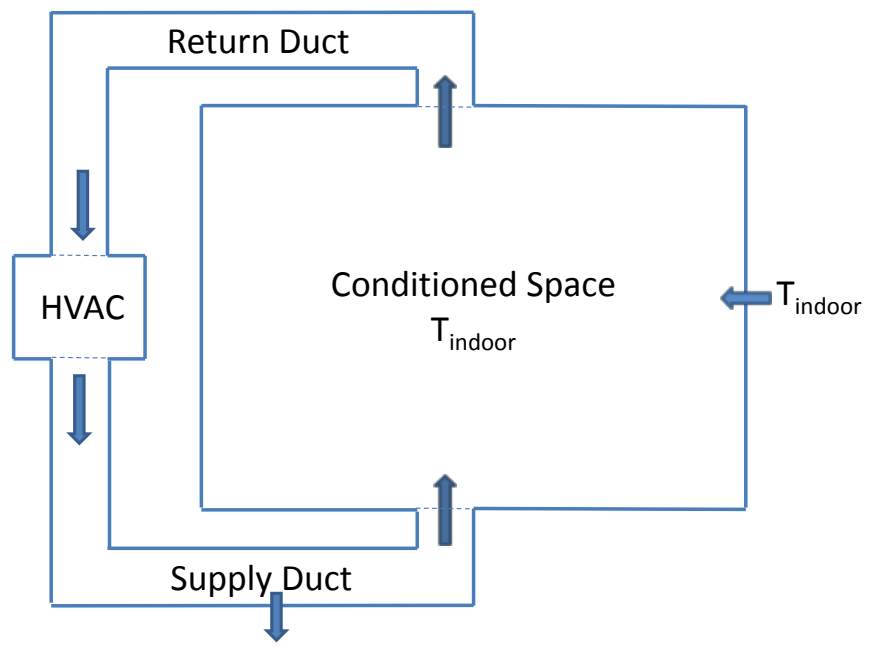

Figure 19. Simple duct model for illustration of heat balance between supply and return ducts.

While equation 1 still gives the energy change between inlet and outlet air streams (which includes heat transfer between the duct and the air stream and the energy contained in the air that leaks from the duct), 
this is not the load placed on the HVAC system. For illustrative purposes if we further simplify the problem by assuming that the supply duct is perfectly insulated then $T_{\text {out }}$ equals $T_{\text {in }}$ and Equation 1 gives

$$
\dot{Q}_{\text {supplyduct }}=\left(\dot{m}_{\text {in }}-\dot{m}_{\text {out }}\right) c_{p} T_{\text {in }}=\dot{m}_{\text {leak }} c_{p} T_{\text {in }}
$$

Equation 2 implies that leakage from a supply duct always represents a loss of energy (or a heating load) regardless of the outdoor temperature - which is not correct. What is not being taken into consideration in AtticSim is that a mass of air equal to the supply duct leakage must be reintroduced to the conditioned space from somewhere. In this case, since more air is leaving the conditioned space through the return duct than is being supplied to the space from the supply duct, outdoor air has to be drawn into the conditioned space to make up the difference. There is an inherent assumption in AtticSim that there is no net mass gain or loss from the ducts. The calculation of the HVAC load due to ducts is only correct if there are no leaks in the ducts or if the mass flow rate leaking from the supply ducts exactly matched the mass flow rate leaking into the return ducts. To correct for this in AtticSim any net mass gain or loss in the conditioned space created by leaks in the duct system has to be compensated. If leaks from the supply ducts exceed leaks into the return ducts then air is drawn into the conditioned space from the outdoors to make up the net difference.

$$
\dot{Q}_{\text {ducts }}=\sum_{i=1}^{N_{\text {ducts }}}\left(\dot{m}_{\text {in }} c_{p} T_{\text {in }}-\dot{m}_{\text {out }} c_{p} T_{\text {out }}\right)_{i}+\dot{m}_{\text {net }} c_{p} T_{\text {outdoor }}
$$

If leaks into the return ducts exceed leaks from the supply ducts then indoor air has to exhausted from the conditioned space to make up the net difference.

$$
\dot{Q}_{\text {ducts }}=\sum_{i=1}^{N_{\text {ducts }}}\left(\dot{m}_{\text {in }} c_{p} T_{\text {in }}-\dot{m}_{\text {out }} c_{p} T_{\text {out }}\right)_{i}-\dot{m}_{\text {net }} c_{p} T_{\text {indoor }}
$$

\section{CORRECTION TO HVAC “ON TIME” FRACTION}

When AtticSim calls the transient duct subroutine (DUCTTR) to calculate performance for an hour it supplies a variable (ONTIME) giving the fraction of time during the hour that the HVAC system is on. AtticSim calculates the number of cycles per hour using Equation 5. A plot of the number of cycles per hour versus the specified on time is shown in Figure 20.

$$
N_{\text {cycles }}=3 * 4 * \text { ONTIME } *(1-\text { ONTIME })
$$

The time that the HVAC is on during a cycle is given by Equations 6, and the time that it is off is given by Equation 7.

$$
\begin{aligned}
& t_{\text {on }}=\text { ONTIME } / N_{\text {cycles }} \\
& t_{\text {off }}=(1-\text { ONTIME }) / N_{\text {cycles }}(7)
\end{aligned}
$$




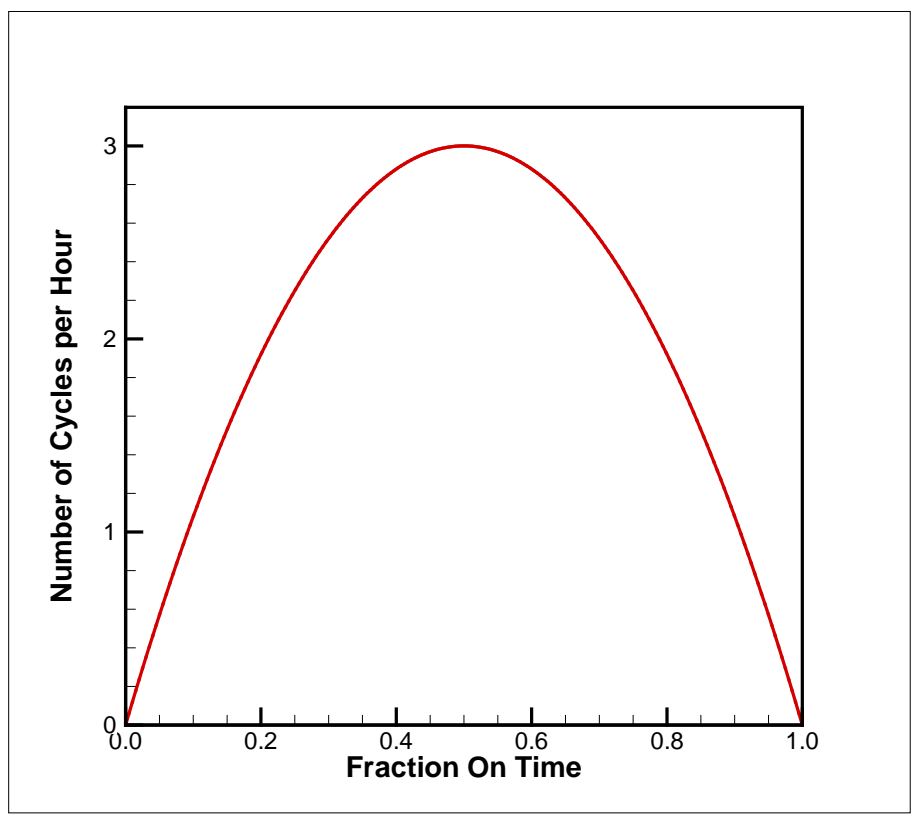

Figure 20. Cycles per hour as a function on ONTIME

During the calculation for an hour AtticSim begins with the HVAC on for time $t_{\text {on }}$ and then turns it off for time $t_{\text {off }}$. This on/off cycle is repeated until the end of the hour is reached. Unfortunately this procedure does not guarantee that the specified on time is achieved for the hour. The problem can be illustrated with a simple example. If ONTIME is specified to be 0.3 then $N_{\text {cycles }}=2.52, t_{o n}=0.119$ hours and $t_{o f f}=0.278$ hours. Figure 21shows a plot of the on/off cycles for an hour. Since the third cycle was not completed during the hour the fraction of time the HVAC ran during the hour is greater than the specified ONTIME. Figure 22 shows a plot of actual ONTIME versus specified ONTIME (left) and percent error (right).

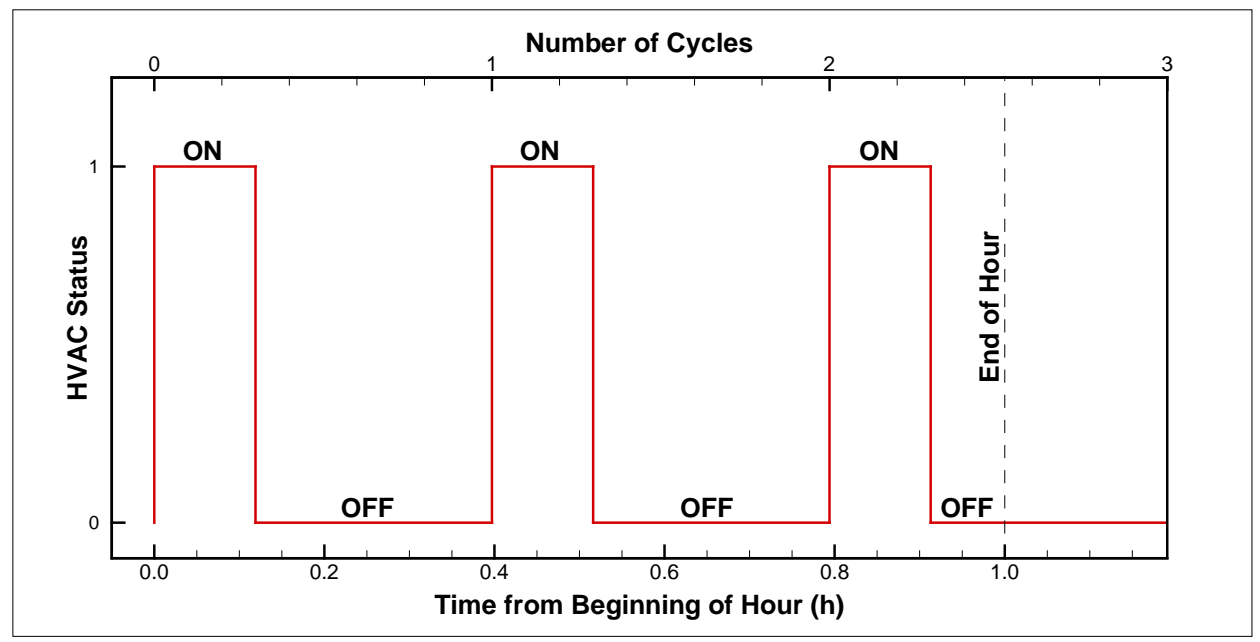

Figure 21. On/Off cycle for ONTIME=0.3 

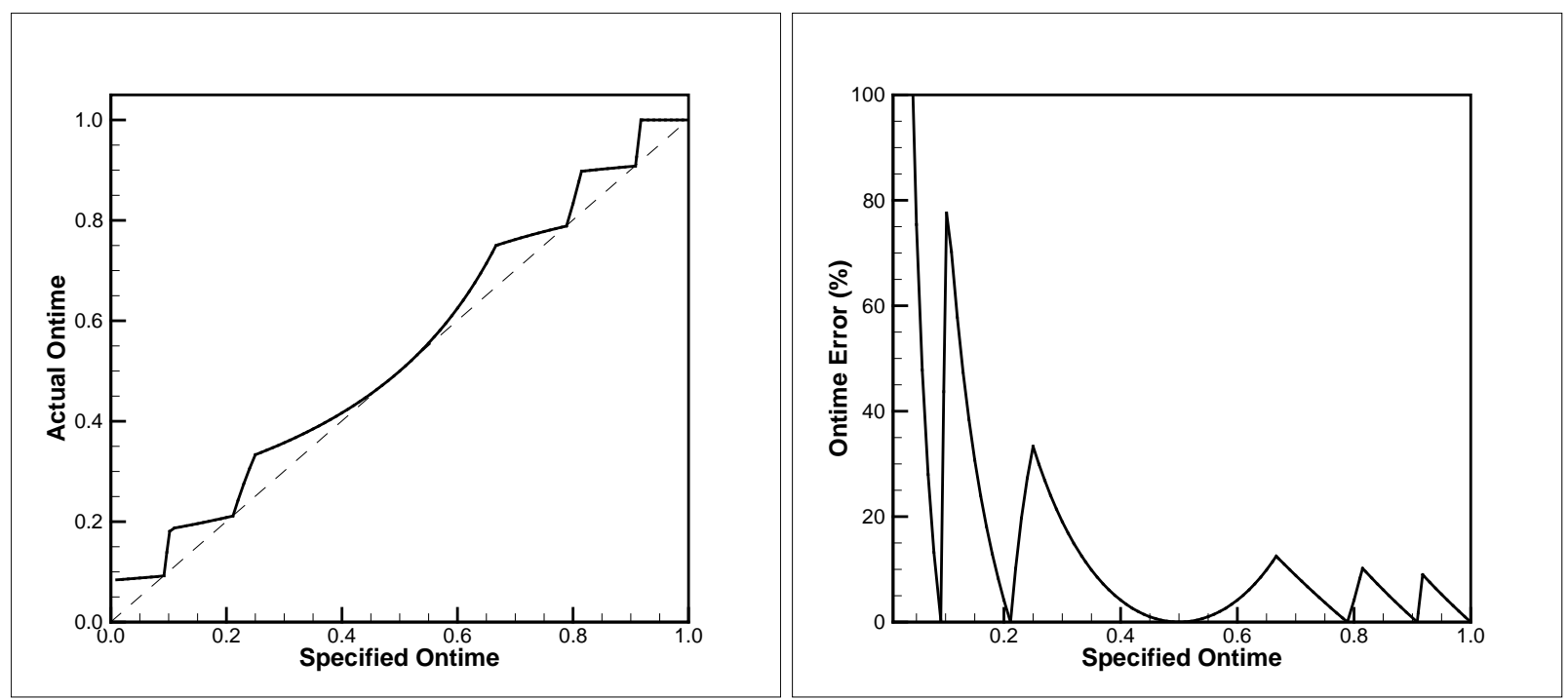

Figure 22. Actual ONTIME versus specified ONTIME (left) and percent error (right)

To correct this discrepancy in specified and achieved ONTIME, AtticSim was modified to always have an integer number of cycles per hour as illustrated in Figure 23.

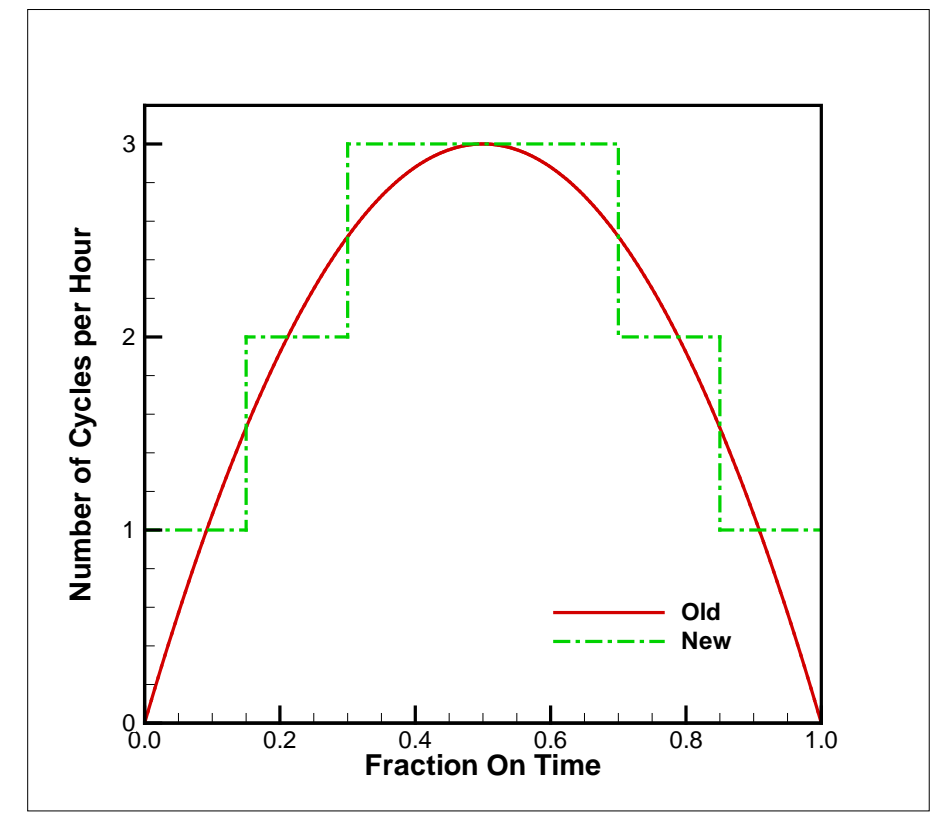

Figure 23. Modified method for calculating cycles per hour

\section{CHANGE IN DUCT LENGTH FOR LARGE BUILDINGS}

When performing its energy balance calculation on a duct AtticSim divides the duct length into a number of equal-length segments. Each segment has a maximum length of 1 foot, and there are a maximum of 100 segments. Thus the maximum length for any duct is 100 feet. However commercial buildings commonly have duct runs much greater than 100 feet in length, so there is a need to remove this restriction from AtticSim. There are two very simple approaches to handle longer ducts: (1) keep the 1 foot segment length but increase the number of segments or (2) keep a maximum of 100 but increase the 
segment length. Both of these approaches have shortcomings. Increasing the number of segments will drastically increase the time required to run a simulation. Increasing the segment length can introduce inaccuracies in the calculations - particularly near the duct entrance where temperatures may be changing rapidly along the duct length. Thus, a third hybrid approach was implemented where the segment length is 1 foot at the duct entrance but each segment along the duct is progressively longer than the previous segment. This allows the code to handle the rapidly changing condition near the entrance, while limiting the number of segments by having longer segments further down the duct where change is much more gradual. Figure 24shows the required growth factor to obtain the desired duct length using 100 segments. Also shown in the figure is the equation used by AtticSim to calculate the growth factor. The equation was obtained by curve fit using the commercial software package TableCurve 2D. This modification was tested by comparing results from a version of AtticSim where the number of 1-foot segments was increase to give the desired length to a version with 100 segments with increasing length down the duct. For the cases tested the two versions gave essentially the same results for duct lengths up to 1000 feet, but the case with 100 increasing-length segments runs much faster.

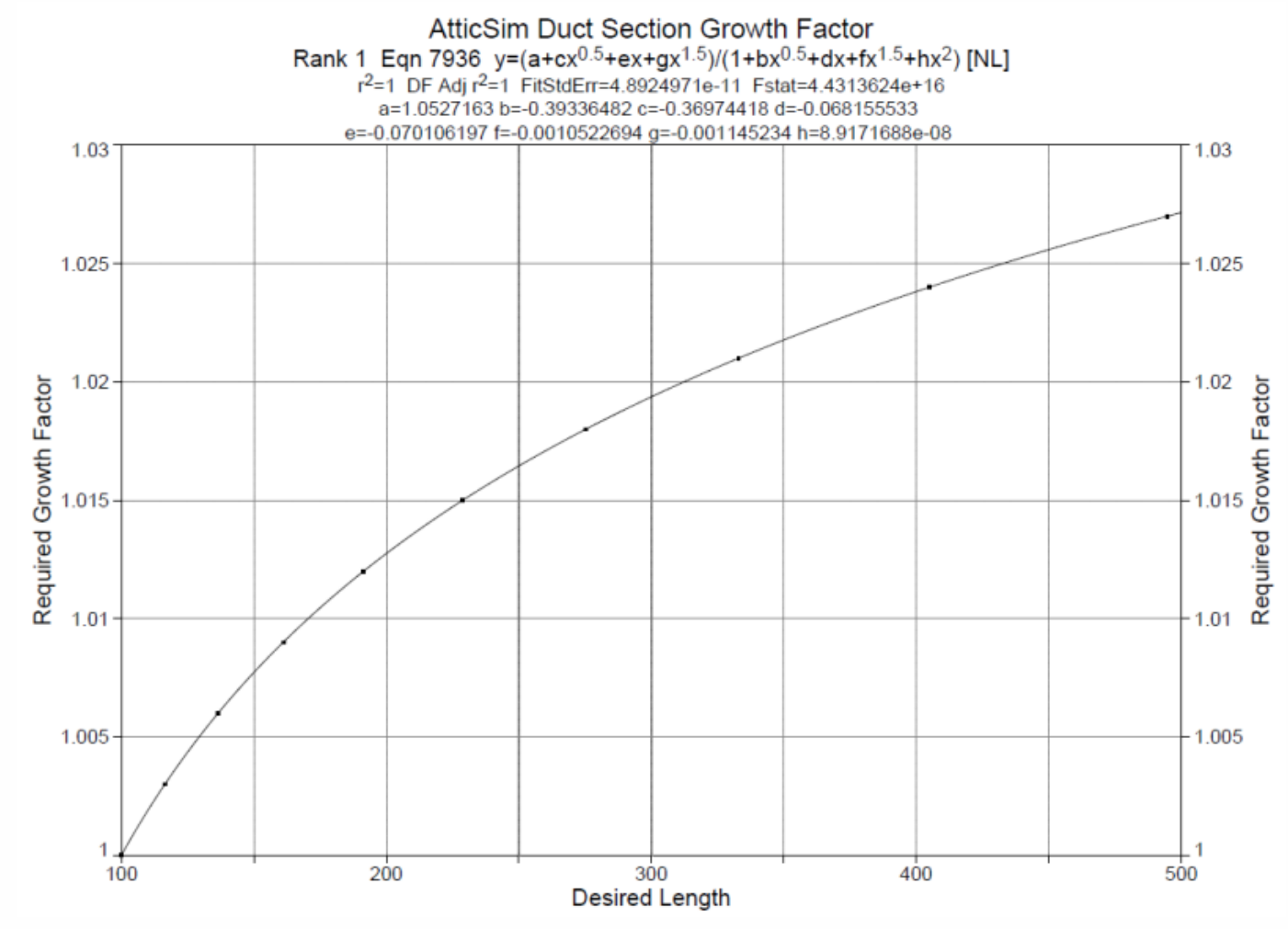

Figure 24. Equation used for model growth factor

\section{LONGER TIME STEP TO SPEED UP EXECUTION}

Since there is a desire to speed up execution of AtticSim, the code was examined to determine if there were any simple changes that might help accomplish this. An obvious place to look is the time step used. AtticSim uses a time step of 20 seconds which seems smaller than might be required to get good results. Therefore the time step was varied in a series of test runs to see how large it could be without adversely impacting the results. When using a fixed time step there can be a problem with obtaining the desired on 
time during an hour since the end of a time step probably will not hit the exact time the HVAC is to be turned on or off. In fact the actual on time can be off as much as one time step in either direction for each cycle. This may have been part of the motivation behind the 20 second time step used. To avoid this problem when going to larger time steps, the time step was adjusted slightly so that there were always an integer number of time steps during the on portion of the cycle. A similar adjustment was made to the time step for the off portion of the cycle. This means that the time steps for the on and off portions of the cycle are slightly different, but the desired on time will always be achieved. Time steps up to 4 minutes were examined. It was concluded that a time step of 2 minutes could be used without adversely impacting the results. A two-minute time step resulted in a code speedup by a factor of 3 to 5 depending on the case being run. 


\section{APPENDIX L: LESSONS LEARNED IN ENSEMBLE COMPARISON OF RSC SIMULATIONS}

User support was provided for analysis on questions arising from the comparison of multiple simulations. A summary of the results are provided in the table below.

Table 3. Example ensemble comparison of RSC differences between gas and electric heating.

\begin{tabular}{|c|c|c|c|c|c|c|c|c|}
\hline \multirow[b]{2}{*}{ City } & \multirow[b]{2}{*}{ St. } & \multirow[b]{2}{*}{$R$-value } & \multicolumn{3}{|c|}{ Gas Heat } & \multicolumn{3}{|c|}{ Electric Heat } \\
\hline & & & $\begin{array}{l}\text { Cooling } \\
\text { Benefit } \\
\end{array}$ & $\begin{array}{l}\text { Heating } \\
\text { Penalty }\end{array}$ & $\begin{array}{r}\text { Net } \\
\text { Impact }\end{array}$ & $\begin{array}{l}\text { Cooling } \\
\text { Benefit }\end{array}$ & $\begin{array}{l}\text { Heating } \\
\text { Penalty }\end{array}$ & $\begin{array}{r}\text { Net } \\
\text { Impact }\end{array}$ \\
\hline Rochester & NY & $\mathrm{R}-20$ & $\$ 101$ & $(\$ 424)$ & $(\$ 323)$ & $\$ 354$ & $(\$ 304)$ & $\$ 50$ \\
\hline Rochester & NY & $\mathrm{R}-25$ & $\$ 89$ & $(\$ 374)$ & $(\$ 285)$ & $\$ 309$ & $(\$ 270)$ & $\$ 39$ \\
\hline Rochester & NY & $R-30$ & $\$ 79$ & $(\$ 336)$ & $(\$ 257)$ & $\$ 274$ & $(\$ 240)$ & $\$ 34$ \\
\hline
\end{tabular}

\section{SIMULATION INFORMATION}

The 6 simulations used in this analysis were replicated with the following files:

1) *_inputs.txt - the form data sent to the server

2) *_base.inp - inputs for the base building

3) *_comp.inp - inputs for the comparison building

4) *_result.htm - the result page that is displayed when the simulation is complete

5) directorylbase_doe2.out - full DOE-2 file of the base simulation output ( 8000 lines of simulation data)

6) directorylbase_readout.out - just the portion of the DOE-2 file relevant for constructing result webpage

Total then monthly (13 columns) with the following 7 lines of energy use data:

Total heating (gas/MBtu)

Total heating (electric/kWh)

Total cooling (electric/kWh)

Fan energy (electric/kWh)

Peak heating (gas/MBtu)

Peak heating (electric/kWh)

Peak cooling (electric/kWh)

7) directorylcomp_doe2.out - full DOE-2 file of the comparison simulation output (lots of simulation data)

8) directorylcomp_readout.out - just the portion of the DOE-2 file relevant for constructing result webpage

This data is publicly available from the following locations:

http://www.roofcalc.com/result/33522_result.htm (R20 gas)

http://www.roofcalc.com/result/33523_result.htm (R20 electric)

http://www.roofcalc.com/result/33524 result.htm (R25 gas)

http://www.roofcalc.com/result/33525_result.htm (R25 electric) 
http://www.roofcalc.com/result/33526_result.htm (R30 gas)

http://www.roofcalc.com/result/33527_result.htm (R30 electric)

\section{RSC DESIGN}

The Department of Energy's (DOE) Roof Savings Calculator (RSC) at http://rsc.ornl.gov was designed to allow comparison of roof and attic assemblies but with all weather, building properties, and HVAC system information kept the same. This was done to limit confusion raised by use cases such as the comparison of different HVAC equipment (something the website GUI doesn't allow). Without such a limitation, many various factors complicate interpretation and comparison ranging over the different HVAC systems, building dynamics, heating/cooling loads, autosizing routines, and unmet hours. These are discussed in further detail below.

\subsection{HVAC SYSTEMS}

Short summary: natural gas and electric heat pumps used by RSC are significantly different. Very different energy savings/performance should be expected when comparing a packaged variable air volume system to a unitary hydronic heat pump system used for the medium office and retail building types.

Detailed summary:

Lines 5993-6007 of 33522 \base_doe2.out (33522 \base_doe2.out:5993-6007) show the following:

$.1 * 3459 *$ SYS1 SYSTEM

.1 \#3460 \# \#\#if \#[ HVAC_Type[] eqs FurnAC ]

$.2 * 3461 * \quad$ SYSTEM-TYPE = PVAVS

$.2 * 3462 *$ HEAT-SOURCE = HOT-WATER

.2 \#3463 \# \#\#if \#[ Furn_AFUE[] eq 0 ]

$.3-3464-\quad$ FURNACE-HIR $\quad=1.0$

.2 \#3465 \# \#\#else

$.3 * 3466 *$ FURNACE-HIR = \#[ $100 /$ Furn_AFUE[] $]$

$<3466>\quad$ FURNACE-HIR $\quad=1.204819322$

.2 \#3467 \# \#\#endif

.1 \#3468 \# \#\#elseif \#[ HVAC_Type[] eqs HeatPump ]

.2 -3469 - SYSTEM-TYPE = HP

.1 \#3470 \# \#\#else

.2 -3471 - Error - HVAC_Type mismatch

.1 \#3472 \# \#\#endif

On the website, "6. Heating Equipment:" default of "Natural gas furnace” corresponds to SYSTEMTYPE=PVAVS whereas "Electric heat pump" corresponds to SYSTEM-TYPE=HP.

The reference manual that explains these systems in more detail can be found here: http://doe2.com/download/DOE-21E/DOE-2ReferenceManualVersion2.1A.pdf

Page 265 shows the difference between the SYSTEM-TYPES: 
PVAVS

Packaged Variable Air Volume System

HP

Unitary Hydronic Heat Pump System
Outside Air, Return Air, Exhaust Fan, Fan Control, Supply Air Temperature Control, Heating Coil Temperature Control, Reheat Coil, Baseboard Heat, Minimun Humidity Control, Maximum Humidity Control, Thermostat, Heat Recovery, Subzones, Variable Flow, Equipment Sizing, Heat Source, Motor Placement, Night Cycle Control, Fan Sizing

Outside Air, Fan Control, Baseboard Heat, Thermostat, Equipment Sizing, Heat Source, Night Cycle Control

The systems are described in great detail...HP (323-326, IV.71-IV.74) and PVAVS (348-351, IV.96IV.99). The most important part is page 496, Table IV.39 regarding the equipment curves hard-coded inside DOE-2. These calculations are used whenever you use the corresponding system types. This has the effect of making the input files small but some detailed analysis is hidden in the background and only special flags allow a modeler to check a simulation run.

\begin{tabular}{|c|c|c|c|c|c|c|c|c|c|}
\hline \multirow{3}{*}{$\begin{array}{l}\text { Default } \\
\text { Curve } \\
\text { U-name }\end{array}$} & \multicolumn{9}{|c|}{$\begin{array}{l}\text { SYSTEM-EQUIPMENT DEFAULT CURVES } \\
\text { Equations are assumed to take the form: } \\
\text { linear, or } z=a+b x \\
\text { bi-linear, or } z=a+b x+d y \\
\text { quadratic, or } z=a+b x+c x^{2} \\
\text { bi-quadratic, or } z=a+b x+c x^{2}+d y^{2}+e y^{2}+f x y \\
\text { cubic, or } z=a+b x+c x^{2}+d x^{3}\end{array}$} \\
\hline & \multirow[b]{2}{*}{ Keyword } & \multirow{2}{*}{\multicolumn{2}{|c|}{$\begin{array}{l}\text { Independent Applicable } \\
\text { Variable(s)* SYSTEM-TYPE }\end{array}$}} & \multicolumn{5}{|c|}{ Default Curve Coefficients } & \multirow[b]{2}{*}{$f$} \\
\hline & & & & a & $\mathrm{b}$ & c & d & e & \\
\hline SDL-C13 & COOL-EIR-FT & WB/OOB & PSZ,PMZS,PVAVS & 0.282094 & -0.005832 & 0.0 & 0.01167 & 0.0 & $\begin{array}{l}w . v \\
0.0\end{array}$ \\
\hline SDL. $-C 15$ & COOL-EIR-FT & WB/WT & HP & 0,41766475 & -0.0044505 & 0.0 & 0.01174025 & 0.0 & 0.0 \\
\hline $\begin{array}{l}\text { * WB } \\
\text { ODB } \\
\text { WT } \\
\text { OWB }\end{array}$ & \multicolumn{4}{|c|}{$\begin{array}{l}=\text { entering wet-bulb temperature }\left({ }^{\circ} \mathrm{F}\right) \\
=\text { outside dry-bulb temperature }\left({ }^{\circ} \mathrm{F}\right) \\
=\text { entering water temperature }\left({ }^{\circ} \mathrm{F}\right)\end{array}$} & $\begin{array}{l}\text { DB } \\
\text { PLR } \\
\text { CFM_PLR }\end{array}$ & \multicolumn{4}{|c|}{$\begin{array}{l}=\text { entering dry-bulb temperature }\left({ }^{\circ} \mathrm{F} \text { ) }\right. \\
=\text { part-load ratio (fraction) } \\
=\text { change in full load capacity as a function } \\
\text { of supply air flow rate }\end{array}$} \\
\hline
\end{tabular}

The coefficients are numerically close (which would mean that the energy required to meet the same load would be similar), however, the independent variable for the HP unit is the wet bulb entering water temperature rather than the outdoor dry bulb temperature. This means in any location where wet bulb water temp is significantly different than the outdoor temp, the difference between a gas furnace and hydronic heat pump system's energy consumption would be proportionately large. This difference is typically larger in a place like Rochester, NY than it would be in Miami, FL. More details not included in this report quantified the impact of these numbers for the R-20 simulation. 


\subsection{AUTOSIZING}

Autosizing is necessary since the size of the building can vary. This has the added benefit of capturing cost savings for properly sizing the HVAC for a given building. However, HVAC system differences (in regard to energy consumption) are compounded by autosizing since simulations of different HVAC systems in the same building could be different tonnage. This was verified to be the case between your R20 and R-30 simulations. Energy consumption would not be the same for two differently sized units, even if they're of the same type, since cycling time and many other performance factors change with HVAC size.

\subsection{UNMET HOURS}

The autosizing routine is fairly aggressive and leads to the common practice of hundreds of unmet hours. An hour is considered unmet if the temperature at the thermostat is below the $~ 2$-degree deadband around the thermostat setpoint (this can be tens of degrees or a fraction of a degree and will count the same). Different systems with different sizes will have a significant difference of unmet hours.

\section{REFERENCES}

Other publications showing development of the calculator, validation of portions to field demonstration data, and visual analysis (in reverse chronological order):

Jones, Chad, New, Joshua R., Sanyal, Jibonananda, and Ma, Kwan-Liu (2012). "Visual Analytics for Roof Savings Calculator Ensembles." In Proceedings of the 2nd Energy Informatics Conference, Atlanta, GA, Oct. 6, 2012. [PDF] [PPT]

Cheng, Mengdawn, Miller, William (Bill), New, Joshua R., and Berdahl, Paul (2011). "Understanding the Long-Term Effects of Environmental Exposure on Roof Reflectance in California." In Journal of Construction and Building Materials, Volume 26, Issue 1, pages 516-26, August 2011. [PDF]

New, Joshua R., Jones, Chad, Miller, William A., Desjarlais, Andre, Huang, Yu Joe, and Erdem, Ender (2011). "Poster: Roof Savings Calculator." In Proceedings of the International Conference on Advances in Cool Roof Research, Berkeley, CA, July 2011. [PDF]

New, Joshua R., Miller, William (Bill), Desjarlais, A., Huang, Yu Joe, and Erdem, E. (2011). "Development of a Roof Savings Calculator." In Proceedings of the RCI 26th International Convention and Trade Show, Reno, NV, April 2011. [DF] [PPT]

Miller, William A., New, Joshua R., Desjarlais, Andre O., Huang, Yu (Joe), Erdem, Ender, and Levinson, Ronnen (2010). "Task 2.5.4 - Development of an Energy Savings Calculator." California Energy Commissions (CEC) PIER Project, ORNL internal report ORNL/TM-2010/111, March 2010, 32 pages.

Miller, William A., Cheng, Mengdawn, New, Joshua R., Levinson, Ronnen, Akbari, Hashem, and Berdahl, Paul (2010). "Task 2.5.5 - Natural Exposure Testing in California." California Energy Commissions (CEC) PIER Project, ORNL internal report ORNL/TM-2010/112, March 2010, 56 pages. 